\title{
Flexural response of aluminium alloy SHS and RHS with internal stiffeners
}

DOI:

10.1016/j.engstruct.2016.04.021

\section{Document Version}

Accepted author manuscript

Link to publication record in Manchester Research Explorer

\section{Citation for published version (APA):}

Su, M. N., Young, B., \& Gardner, L. (2016). Flexural response of aluminium alloy SHS and RHS with internal stiffeners. Engineering Structures, 121, 170-180. https://doi.org/10.1016/j.engstruct.2016.04.021

\section{Published in:}

Engineering Structures

\section{Citing this paper}

Please note that where the full-text provided on Manchester Research Explorer is the Author Accepted Manuscript or Proof version this may differ from the final Published version. If citing, it is advised that you check and use the publisher's definitive version.

\section{General rights}

Copyright and moral rights for the publications made accessible in the Research Explorer are retained by the authors and/or other copyright owners and it is a condition of accessing publications that users recognise and abide by the legal requirements associated with these rights.

\section{Takedown policy}

If you believe that this document breaches copyright please refer to the University of Manchester's Takedown Procedures [http://man.ac.uk/04Y6Bo] or contact uml.scholarlycommunications@manchester.ac.uk providing relevant details, so we can investigate your claim.

\section{OPEN ACCESS}


Su, M., Young, B. and Gardner, L. (2016), "Flexural resistance of aluminium alloy SHS/RHS with internal stiffeners”, Engineering Structures, 121: 170-180.

\title{
Flexural response of aluminium alloy SHS and RHS with
}

\section{internal stiffeners}

\author{
Mei-Ni Su ${ }^{1}$, Ben Young ${ }^{2}$ and Leroy Gardner ${ }^{3}$
}

\begin{abstract}
Tubular profiles, such as square and rectangular hollow sections (SHS and RHS) are widely used in a range of structural engineering applications. Their thin-walled nature means that local buckling is a key design concern, which is usually addressed by adhering to specified slenderness limits. An alternative approach is to employ local plate stiffeners, which can be practically achieved in extruded aluminium alloy sections through the introduction of internal cross stiffeners. The flexural behaviour and design of aluminium alloy SHS and RHS with internal stiffeners is the subject of investigation of the present paper. The primary aims of the study are to generate experimental and numerical data for these new types of cross-section in bending, as well as to assess the applicability of different approaches to their design at cross-sectional and system levels. First, an experimental investigation was performed on aluminium alloy SHS and RHS beams with internal stiffeners subjected to three-point bending, four-point bending and five-point bending (i.e. continuous beams over three supports) of three different configurations. Finite element (FE) models were also developed and validated against the presented test data. Once validated, the models were employed to generate additional data through numerical parametric studies. Comparisons are then made between the experimental/numerical capacities and the
\end{abstract}


design capacities predicted using international design specifications for aluminium alloy structures, as well as the continuous strength method (CSM). The design strengths predicted by the American and Australian/New Zealand specifications were found to be conservative, while improved predictions were achieved by Eurocode 9. The most accurate and consistent predictions were obtained using the CSM, which was able to capture the significant observed strain hardening at the cross-sectional level and moment redistribution at the global system level.

KEY WORDS: Aluminium alloys; Bending moment capacities; Continuous beams; Continuous strength method; Experimental investigation; Internal stiffeners; Numerical analyses; Simply supported beams; Square and rectangular hollow sections; Structural design; Testing

\footnotetext{
${ }^{1}$ Assistant professor, Dept. of Civil Engineering, Shenzhen University, Shenzhen, China

2 Professor, Dept. of Civil Engineering, The Univ. of Hong Kong, Pokfulam Road, Hong Kong. E-mail: young@hku.hk

${ }^{3}$ Professor, Dept. of Civil and Environmental Engineering, Imperial College London, London SW7 2AZ, UK. Email: leroy.gardner@imperial.ac.uk
}

\section{Introduction}

Aluminium alloys are used across a range of structural engineering applications, with square and rectangular hollow sections (SHS and RHS) being a popular cross-section shape. While SHS and RHS are commonly adopted, the extrusion process enables more complex shapes to be readily produced in aluminium alloys [1]. This can be particularly beneficial for enhancing resistance to local buckling through, for example, the addition of internal stiffeners. In this study, the flexural behaviour and ultimate bending capacity of square and rectangular hollow sections with internal cross stiffeners are investigated through experimentation and numerical modelling. The load- 
deflection histories of the test specimens as well as the observed failure modes are reported. Further data are also generated through finite element modelling.

Investigations into the flexural behaviour of aluminium alloy beams have been carried out by many researchers in recent years - for both square and rectangular hollow section members [2-5] and thin-walled members with stiffeners [6-9]. To date, in light of the experimental and numerical results, the key aims of the present study are to investigate the importance of strain hardening and the applicability of plastic design to aluminium alloy structures, since previous research [10-13] has highlighted scope for improved design efficiency through consideration of these effects. Two different types of aluminium alloys - normal strength aluminium alloy 6063-T5 and high strength aluminium alloy 6061-T6, were examined to consider the influence of strain hardening on different tempers.

The use of continuity in a structural system can bring about benefits, such as increased loadcarrying capacity and reduced deflections. Hence, the importance of moment redistribution in indeterminate aluminium alloy structures is considered herein through the study of two-span continuous beams. Theofanous et al. [14] reported that when considering moment redistribution in stainless steel continuous beams, the design capacities were found to be improved by around $10 \%$ and offer more accurate prediction of the test response. However, although structural design guidance is widely available for aluminium alloys, global plastic design is generally not permitted in international specifications such as the Aluminium Design Manual [15] and Australian/New Zealand Standards [16]. Eurocode 9 (EC9) [17] was the first code to allow full inelastic analysis of aluminium alloy structures [18], including the plastic hinge method in Annex $\mathrm{H}$ for continuous beams with Class 1 cross-sections. Available experimental data from the literature on 
indeterminate aluminium alloy structures is rather limited, with the key studies being reported on continuous beams [19-21].

In this investigation, 6 three-point bending tests (to investigate the flexural response under a moment gradient), 5 four-point bending tests (to study the flexural response under uniform bending moment) and 19 continuous tests (to investigate moment redistribution and the ultimate load carrying capacities of indeterminate structures) have been conducted, and the results of 60 numerical simulations of simply supported beams and 90 simulations of continuous beams are presented. All tested and simulated specimens are aluminium alloy SHS and RHS with internal stiffeners. In the final part of this paper, the capacity predictions from three international aluminium alloy design specifications [15-17] are evaluated against the generated test and numerical data. A deformation-based design approach, the continuous strength method (CSM) [19, 22, 23], is also assessed. The CSM allows for moment redistribution as well as a systematic exploitation of strain hardening. The key findings of the comparisons are presented and discussed.

\section{Experimental investigation}

The experimental program comprised 6 three-point bending tests, 5 four-point bending tests and 19 five-point bending continuous beam tests. A series of different cross-section sizes, defined using the symbols illustrated in Figure 1, were examined. The cross-sectional dimensions shown in Table 1 are the average measured values for each test specimen in this study. The average measured material properties for each test specimen, determined following the testing procedure described in [24,25], are also presented in Table 1, where the following symbols are used: $E$ is the Young's Modulus, $f_{y}$ is the material yield stress (taken as the $0.2 \%$ proof stress), $f_{u}$ is the material ultimate stress, $\varepsilon_{u}$ is the strain corresponding to the ultimate tensile stress of the material and $\varepsilon_{f}$ is the plastic strain corresponding to the material fracture. 
The specimens were labelled according to the cross-sectional dimensions, type of material and the test configuration. For example, the label “+H50×95×10.5B3” defines an RHS with internal stiffeners of the same thickness as the outer walls of the section. In the label, the "+" refers to specimens with internal stiffeners, "H” means high strength aluminium alloy 6061-T6, with crosssectional dimensions of width $(50 \mathrm{~mm}) \times$ height $(95 \mathrm{~mm}) \times$ thickness $(10.5 \mathrm{~mm})$. If the label has the letter "N", it means the specimen is normal strength aluminium alloy 6063-T5. The symbol "B3” following the dimensions refers to the three-point bending tests, as shown in Figures 2 and 3, while the other configurations are indicated as "B4" for four-point bending (Figures 4 and 5) and "B5" for five-point bending (Figures 6 and 7). Meanwhile there are three different configurations for the five-point bending tests, which are signified as "B5I" for configuration I, “B5II” for configuration II and “B5III" for configuration III. If a test is repeated, a letter "R" is included at the end of the label.

For all specimens, steel bearing plates were placed between the test specimens and the rollers/half rounds at the loading and support points for the purpose of spreading the concentrated loads. Stiffening steel plates of $100 \mathrm{~mm}$ width and $10 \mathrm{~mm}$ thickness were also clamped to the webs of the relatively slender sections $(+\mathrm{H} 95 \times 95 \times 4.3)$ at the loading points and the supports to prevent web crippling. A servo-controlled hydraulic testing machine was used to apply compressive force by displacement control to the specimens at a constant rate of $0.8 \mathrm{~mm} / \mathrm{min}$. A summary of the test results is given in Tables 2 and 3.

\subsection{Three-point bending tests}


In the three-point bending tests, the simply supported specimens were loaded at the mid-span, as shown in Figures 2 and 3. The beam span between the supports was $600 \mathrm{~mm}$. One LVDT was used to measure the vertical deflection at mid-span and two LVDTs were placed at each end of the specimens to measure the end rotation.

Full moment-end rotation graphs obtained from the three-point bending tests are presented in Figure 8 . Two specimens $+\mathrm{H} 50 \times 95 \times 10.5 \mathrm{~B} 3$ and $+\mathrm{H} 95 \times 50 \times 10.5 \mathrm{~B} 3$ failed by material yielding and inelastic local buckling, while the remainder of the specimens failed by tensile material fracture at mid-span (Figure 9). It should be noted that significant visual local buckling was not clearly apparent in the tests.

\subsection{Four-point bending tests}

In the four-point bending tests, the specimens were loaded symmetrically at two points through a spreader beam, as shown in Figures 4 and 5. The span of the beams was $900 \mathrm{~mm}$, with the loads applied at third points. Three LVDTs were used to measure the vertical deflection of the beams at mid-span and at the loading points, respectively, in order to obtain the mid-span deflection and curvature in the constant moment region. Two further LVDTs were placed at each end of the beams to measure the end rotation.

Moment-curvature graphs obtained from the four-point bending tests are presented in Figure 10. Similar to three-point bending tests, specimens either failed by material yielding and inelastic local buckling or tensile material fracture at mid-span (Figure 11); meanwhile, no significant visual local buckling was observed during the tests. 
During the bending tests, the internal cross stiffeners were shown to effectively impede local buckling of the compression flanges. As shown in Figure 12, the stiffeners acted as nodal lines, dividing the compression flange into two equal halves, resulting in a reduction in plate slenderness by a factor of two and an increase in load-bearing and deformation capacity.

\subsection{Five-point bending tests}

The overall nominal length of the continuous beams was $1690 \mathrm{~mm}$. Three symmetrical five-point bending configurations were employed in this study. In loading configuration I, the distance between the loading points and the end supports $\left(\mathrm{L}_{1}\right)$ and the loading points and the central support $\left(\mathrm{L}_{2}\right)$ were all equal to $400 \mathrm{~mm}$, while in the configurations II and III, the loads were applied at $L_{2}=266.7 \mathrm{~mm}$ (i.e. the loads were at one third of the span from the central support) and $L_{2}=533.3 \mathrm{~mm}$ (i.e. the loads were at two thirds of the span from the central support), respectively, as illustrated in Figure 6. The loading was applied at two points through a spreader beam (see Figure 7). Two LVDTs were used to measure the vertical deflection at the loading points. Two additional LVDTs were placed $150 \mathrm{~mm}$ either side of the mid-span, in order to estimate the midspan rotation. Two further LVDTs were placed at each end of the beams to measure the end rotations.

The specimens failed principally by the formation of a plastic collapse mechanism comprising three plastic hinges and by material tensile fracture. For the loading configurations I and II, the first plastic hinge formed at the central support while the latter two plastic hinges formed at the loading points. In configuration III, the plastic hinges formed in the reverse sequence. Eventually all specimens fractured at the central support or at the loading points, though in some cases this was after the peak load had been attained. Significant local buckling was generally not visible in the test specimens. In all cases, the ultimate loads attained in the tests were found to be beyond 
the theoretical loads corresponding to the occurrence of the first plastic hinge and the calculated plastic collapse loads. The load-deflection graphs for all five-point bending test specimens are presented in Figure 13, and a typical deformed specimen $(+\mathrm{N} 95 \times 50 \times 10.5 \mathrm{~B} 5 \mathrm{I})$ exhibiting three distinct plastic hinges is shown in Figure 14.

\section{Numerical analyses}

Numerical analyses were carried out in parallel with the experimental studies. The general purpose finite element (FE) package ABAQUS version 6.10 [26] was employed to simulate the beam experiments and to perform parametric investigations. The numerical parametric studies were conducted to assess the effect of key parameters, such as cross-section slenderness, crosssection aspect ratio and moment gradient on the strength, strain hardening and moment redistribution behaviour of aluminium alloy beams.

\subsection{Numerical modelling approach and validation of models}

The reduced integration four-nodded doubly curved shell element S4R was employed in all FE models [27]., with a chosen mesh size of $10 \mathrm{~mm} \times 10 \mathrm{~mm}$ Bearing plates were modelled using 10 mm thick solid elements. Hard contact in the normal direction and friction penalty contact (with the friction coefficient $=0.1$ ) in the tangential direction were adopted between the solid plate (master surface) and the beam surface (slave surface). Simple support conditions were simulated by restraining the relevant degrees of freedom at the bottom flanges [28]. The beams were restrained longitudinally at the mid-span only. The material nonlinearity was included in the FE models by specifying sets of values of true stress and log plastic strain to define a piecewise linear response 
The measured geometric and material properties from the test specimens were employed in the corresponding FE models for the validation study. Residual stresses were not measured in the experimental work and not explicitly modelled in the simulations [29-31]. Initial local geometric imperfections were included in the numerical models in the form of the lowest regular elastic local buckling mode shape, as obtained from linear eigenvalue buckling analyses. The initial local geometric imperfection amplitude was defined as $0.2 \mathrm{~mm}$, which represented the average local imperfection amplitudes measured in the test specimens [32]. Nonlinear analyses of the models were carried out by means of the modified Riks procedure [26]. Since tensile material fracture was the governing failure mode for a number of the test specimens, tensile strains were monitored in the simulated beams, and the point of tensile fracture was defined as that when the maximum strain exceeds the material fracture strain $\varepsilon_{f}$ obtained from tensile coupon tests; for cases where fracture occurred prior to the attainment of the peak load from the numerical model, this became the governing failure mode, as shown for the + N95×50×10.5B5I specimen in Figure 15 .

The experimental and numerical ultimate resistances are compared in Tables 4 and 5, and may be seen to be in good overall agreement. The general shape of the moment-deflection curves from the FE models also matched closely those obtained from the experiments (Figure 15). The test failure modes were also well predicted by the FE models, where no significant local buckling was observed. Overall, it may be concluded that the FE models are able to capture accurately the experimentally observed structural behaviour of the aluminium alloy beams.

\subsection{Numerical parametric studies}

Upon validation of the developed numerical models, parametric studies were carried out, generating 60 numerical results for simply supported beams (Table 6) and 90 numerical results for continuous beams (Table 7). Both major and minor axis bending were modelled. The material 
properties of a typical high strength aluminium alloy tube $\mathrm{H} 64 \times 64 \times 3.0$ (a specimen reported in [4] with $f_{y}=233.8 \mathrm{MPa}$ and $f_{u}=248.4 \mathrm{MPa}$ ) and a typical normal strength aluminium alloy tube $+\mathrm{N} 95 \times 50 \times 10.5$ were employed in the models to represent high strength and normal strength aluminium alloys, respectively. A wide spectrum of aspect ratios $b / h(0.28-3.62)$ and plate element width-to-thickness ratios $b / t(3.40$ - 26.50), covering the four cross-section classes, were considered in the parametric studies. Cross-sections with outer wall dimensions up to $180 \mathrm{~mm}$ and thickness up to $9.0 \mathrm{~mm}$ were modelled. The distance between the supports and the loading points varied from $400 \mathrm{~mm}$ to $900 \mathrm{~mm}$.

\section{Comparison of test and numerical results with design capacities}

In this section, the experimental and numerical ultimate resistances, i.e. $M_{u}$ for the simply supported beams and $F_{u}$ for the continuous beams, are compared with the design strengths predicted using the American $\left(M_{A A}\right.$ or $\left.F_{A A}\right)$ [15], Australian/New Zealand $\left(M_{A S / N Z S}\right.$ or $\left.F_{A S / N Z S}\right)$ [16] and European $\left(M_{E C 9}\right.$ or $\left.F_{E C 9}\right)$ [17] specifications for aluminium alloy structures, as shown in Tables 2, 3 and 8, as well as Figures 16-18. All comparisons made herein with EC9 (2007) use the more favourable Annex $\mathrm{F}$ approach for simply supported beams and Annex $\mathrm{H}$ approach for continuous beams. In addition, the predictions of the CSM $\left(M_{c s m}\right.$ or $\left.F_{c s m}\right)[19,22,23]$ are also evaluated against the experimental and numerical results. The comparisons were performed using the measured material properties and geometries, with all safety factors set equal to unity.

\subsection{Simply supported beams (three-point and four-point bending)}

The ultimate bending moments from the 11 experiments and 60 FE simulations on simply supported aluminium alloy beams are used herein to assess the accuracy of the four different design methods introduced above (the AA, the AS/NZS, EC9 and the CSM) [15-17, 19, 22, 23], as shown in Tables 2 and 8, as well as Figures 16 and 17. 


\subsubsection{International design specifications}

There are a number of established international aluminium alloy structural design specifications. The American Aluminium Design Manual (AA) [15] provides design rules for aluminium alloy beams, in which a nominal weighted average design moment is determined as set out in Chapter F8.3 of Part I of the code. The design flexural capacity given in the Australia/New Zealand (AS/NZS) Standard [16] is the product of the elastic section modulus and a weighted average stress, determined on the basis of the stresses in the compressed portion of the section. Eurocode 9 [17] provides design rules for cross-section resistance in Section 6.2.5 of the code, but also presents an alternative method in Annex F for Class 1 sections, in which a correction factor $\alpha_{M, j}$ is adopted to take into account strain hardening. For the other cross-sections, EC9 defines the resistance as the yield stress $f_{y}$ multiplied by the plastic modulus $W_{p l}$ for Class 2 sections and by the elastic modulus $W_{e l}$ for Class 3 sections.

In comparison to the test and FE results for the simply supported beams, the predictions of the AA [15] and AS/NZS [16] are rather conservative, with mean values for $M_{u} / M_{A A}$ and $M_{u} / M_{A S / N Z S}$ of 1.40 and 1.66, respectively and corresponding coefficients of variation (COV) of 0.207 and 0.233. Meanwhile, EC9 [17], with Annex F applied to the Class 1 cross-sections yields more accurate predictions with a mean value of $M_{u} / M_{E C 9}$ of 1.27 and a COV of 0.150 . The improved accuracy arising from the use of Annex F of EC9 [17] is due to the consideration of strain hardening for Class 1 sections..

\subsubsection{Continuous strength method for determinate structures}

The development and application of the continuous strength method (CSM) for the aluminium alloy flexural members have been described in previous studies [19, 22]. The CSM is a 
deformation based design framework that allows for the beneficial influence of strain hardening for all non-slender cross-sections. The two main features of the CSM are: (1) a base curve defining a continuous relationship between local slenderness $\bar{\lambda}_{p}$ and cross-section deformation capacity; and (2) a strain hardening material model using a strain hardening modulus $E_{\text {sh }}$, as given in Eq. (1).

$$
E_{s h}=\frac{f_{u}-f_{y}}{0.5 \varepsilon_{u}-\varepsilon_{y}}
$$

where the strain at the ultimate stress $\varepsilon_{u}$ may be approximated from $\varepsilon_{u}=0.13\left(1-f_{y} / f_{u}\right)+0.059$.

Following comparisons with the test and FE results, a mean value of test (or FE) to predicted CSM moment $M_{u} / M_{\text {csm }}$ of 1.18 with a COV of 0.153 was obtained. Overall, the CSM approach provides the most accurate predictions of the bending capacity among the considered design approaches, with up to an approximately 50\% improvement compared to the AS/NZS predictions. The results show that strain hardening plays an important role in the flexural capacities of aluminium alloy stocky sections, and that its influence can be effectively captured by the CSM [22].

\subsection{Continuous beams (five-point bending)}

The results of the 19 experiments and 90 numerical simulations on aluminium alloy continuous beams obtained in the present study are compared with the design capacities of the three international specifications [15-17] and the CSM [19] in order to assess their design accuracy for indeterminate aluminium alloy structural systems. The comparative results are summarized in Tables 3 and 8, and are also plotted in Figure 18. 


\subsubsection{International design specifications}

The AA $\left(F_{A A}\right)[15]$ and AS/NZS ( $\left.F_{A S / N Z S}\right)[16]$ design methods use elastic global analysis and the predicted failure loads of the continuous beams are determined when the most heavily loaded cross-section reaches its ultimate resistance. However, the approaches and parameters that are used to calculate the cross-section resistance are different in the two specifications, as outlined in the previous section. According to EC9 [17], the plastic hinge method in Annex $H$ applies principally to Class 1 sections only, but can be also used for Class 2 and 3 sections provided specific account of the effects of local buckling are taken into consideration. In this study, the plastic hinge method $\left(F_{E C 9}\right)$ is only applied to Class 1 cross-sections, while global elastic analysis is used for specimens of other cross-section classes. Further details may be found in Su et al. [19].

The mean values of the ultimate load to predicted resistances ratios for the three design specifications, $F_{U} / F_{A A}, F_{U} / F_{A S / N Z S}$ and $F_{U} / F_{E C 9}$ are $1.70,2.02$ and 1.37 , with corresponding COVs of $0.251,0.276$ and 0.178 , respectively. Among the considered specifications, the AS/NZS [16] specification provides the most conservative predictions, while the EC9 [17] provisions yield the most accurate predictions. Overall, the predictions of all three specifications are rather conservative, particularly for the more stocky cross-sections, as shown in Figure 18. The comparisons indicate that the accuracy of the plastic hinge method stems from the consideration of both plastic global analysis (i.e. moment redistribution) and strain hardening.

\subsubsection{Continuous strength method}

The continuous strength method (CSM) [19] for indeterminate structures combines the merits of traditional plastic analysis, considering the formation of a plastic collapse mechanism as the failure condition, and an accurate assessment of the cross-section moment capacity, allowing for strain hardening. Besides the two key components of the CSM as mentioned in Section 4.1.2, 
another key diversion of the CSM from the plastic hinge method is the theoretical cross-section strain ratios at the hinges being proportional to the hinge rotation ratios (i.e. the capacity is related to the strain demand), as described in [19]

The comparison of the test and numerical results with the CSM predictions reveal a mean value of $F_{u} / F_{c s m}$ of 1.25 and a COV of 0.165 . The CSM [19] for indeterminate structures provides the most precise predictions of the test and numerical results, with the mean strength prediction ratios being closest to unity and the COV being the lowest, by allowing moment redistribution and accounting for strain hardening in the calculation of cross-section resistance.

\section{Conclusions}

A total of 30 aluminium alloy beams of square and rectangular hollow sections with internal cross stiffeners, subjected to three-point bending, four-point bending and five-point bending, have been tested in this study. The specimens were Class 1 sections according to Eurocode 9. Numerical analyses were also performed to supplement the experimental programme, through the generation of 150 parametric results. The combined data set of experimental and numerical results was used to assess the accuracy of three international design specifications: the Aluminium Design Manual, the Australian/New Zealand Standard and Eurocode 9 as well as the continuous strength method (CSM). The results revealed that the three current design specifications underestimate the ultimate capacity of both simply supported beams and continuous beams with hollow cross-sections and internal stiffeners. However, the CSM, which considers strain hardening at the cross-section level and moment redistribution at the global system level, was shown to provide accurate and consistent strength predictions for aluminium alloy square and rectangular hollow sections with internal stiffeners. Thus, it is recommended to use the Continuous Strength Method in the design of aluminium alloy stiffened SHS and RHS structural members. 


\section{Acknowledgements}

The research work in this paper was supported by a grant from The University of Hong Kong under the seed funding program for basic research. The authors are also grateful to Mr Yiran Li for his assistance in the experimental programme as part of his final year undergraduate research project at The University of Hong Kong.

\section{Notation}

$B$

$=$ Section width

$b$

$=$ Flat width of flange

$E$

$=$ Young's modulus

$E_{\text {sh }}$

$=$ Strain hardening modulus

$f_{y}$

$=$ Yield strength, taken as the $0.2 \%$ proof stress

$f_{u}$

$=$ Ultimate tensile strength

$F_{A A}$

= Ultimate load predicted by the AA

$F_{\text {AS/NZS }}$

= Ultimate load predicted by the AS/NZS

$F_{c S m}$

$=$ Ultimate load predicted by the CSM

$F_{\text {design }}$

$=$ Ultimate load predicted by different design methods

$F_{E C 9}$

= Ultimate load predicted by the plastic hinge method in Annex H of EC9

$F_{\text {exp }}$

$=$ Experimental ultimate load

$F_{F E}$

= Ultimate load obtained from FE models

$F_{u}$

$=$ Experimental and numerical ultimate load

$H$

$=$ Section height 


$\begin{array}{ll}h & =\text { Flat height of web } \\ L & =\text { Member length } \\ M_{A A} & =\text { Ultimate moment capacity predicted by the AA } \\ M_{A S / N Z S} & =\text { Ultimate moment capacity predicted by the AS/NZS } \\ M_{c S m} & =\text { Ultimate moment capacity predicted by the CSM } \\ M_{d e s i g n} & =\text { Ultimate moment capacity predicted by different design methods } \\ M_{E C 9} & =\text { Ultimate moment capacity predicted by Annex F of EC9 } \\ M_{e x p} & =\text { Eltimate moment obtained from FE models } \\ M_{F E} & =\text { Ultimate moment obtained from either test or FE models } \\ M_{u} & =\text { Wall thickness } \\ t & =\text { Elastic modulus of effective section } \\ W_{e f f} & =\text { Elastic section modulus } \\ W_{e l} & =\text { Plastic section modulus } \\ W_{p l} & =\text { Material fracture strain } \\ \varepsilon_{f} & \text { Elastic buckling stress } \\ \bar{\lambda}_{c r} & \end{array}$

\section{References}

[1] Mazzolani, F.M. (1995), Aluminium alloy structures $2^{\text {nd }}$. E\&FN Spon Press.

[2]Mennink J., Soetens F., Snijder H.H. (2005) "Cross-sectional stability of aluminium extrusions with arbitrary cross-sectional shapes - experimental and numerical research”, Heron, 50 (2): 69-92. 
[3]Manganiello M., De Matteis G., Landolfo R (2006). "Inelastic flexural strength of aluminium alloys structures” Engineering Structures, 28 (4): 593-608.

[4] Kutanova N., Peköz T., Soetens F. (2010) "Distortional elastic buckling for aluminium: Available prediction models versus design specifications”, Heron, 55 (3-4): 251-268.

[5] Guo X., Xiong Z., Shen Z. (2015) "Flexural-torsional buckling behaviour of aluminium alloy beams”, Frontiers of Structural and Civil Engineering, 9 (2): 163-175.

[6] Höglund T. (1997) "Shear buckling resistance of steel and aluminium plate girders", ThinWalled Structures, 29 (1-4): 13-30.

[7] Shi Y. J., Wang Y.Q., Cheng M., Yuan H.X. (2010), “Analysis of shear strength of thin plate aluminum girders” Gongcheng Lixue/Engineering Mechanics, 27 (9): 69-73.

[8] Brando G., De Matteis G. (2011), "Experimental and numerical analysis of a multi-stiffened pure aluminium shear panel”, Thin-Walled Structures, 49 (10): 1277-1287.

[9] Brando G., De Matteis G. (2014), "Design of low strength-high hardening metal multistiffened shear plates” Engineering Structures, 60: 2-10.

[10] Moen, L.A., Hopperstad, O.S. and Langseth M. (1999). "Rotational capacity of aluminium beams under moment gradient. I: experiments.” Journal of Structural Engineering, ASCE 125(8), 910-920.

[11] Zhu, J.H. and Young, B. (2006). "Experimental investigation of aluminum alloy thin-walled tubular members in combined compression and bending." Journal of Structural Engineering, ASCE 132(12), 1955-1966.

[12] Zhu, J.H. and Young, B. (2009). "Design of aluminum alloy flexural members using direct strength method.” Journal of Structural Engineering, ASCE 135(5), 558-566.

[13] Kim, Y. and Peköz, P. (2010). "Ultimate flexural strength of aluminum sections.” Thinwalled structures 48(10-11), 857-865

[14] Theofanous, M., Saliba, N., Zhao, O. and Gardner, L. (2014) "Ultimate response of stainless steel continuous beams.” Thin-Walled Structures, 83, 115-127.

[15] Aluminum Association (AA). (2010). Aluminum design manual. Washington, D.C.

[16] Australian/New Zealand Standard (AS/NZS). (1997). "Aluminum structures part 1: Limit state design.” AS/NZS 1664.1:1997, Standards Australia, Sydney, Australia.

[17] European Committee for Standardization (EC9) (2007). "Eurocode 9: Design of aluminium structures-Part 1-1: General rules-General rules and rules for buildings.” BS EN 1999-11:2007, CEN. 
[18] De Matteis, G., Moen, L. A., Langseth, M., Landolfo, R., Hopperstad, O.S. and F. M. Mazzolani (2001), "Cross-sectional classification for aluminum beams-parametric study", Journal of Structural Engineering, ASCE, 127(3), 271-279

[19] Su, M., Young, B. and Gardner, L. (2014), "Continuous beams of aluminum alloy tubular cross-section - part II: parametric study and design”, Journal of Structural Engineering, ASCE, 140(9), 04014233.

[20] Panlilo, F. (1947). “The theory of limit design applied to magnesium alloy and aluminum alloy structures.’’ J. Royal Aeronautical Soc., pp. 534-571.

[21] Welo T. (1991) Inelastic deformation capacity of flexurally-loaded aluminium alloy structures. Ph.D. thesis. Trondheim (Norway): Division of Structural Engineering, The Norwegian Institute of Technology

[22] Su, M., Young, B. and Gardner, L. (2014), “Deformation-based design of aluminium alloy beams” Engineering Structures, 80: 339-349.

[23] Afshan, S. and Gardner, L. (2013) "The continuous strength method for structural stainless steel design” Thin-Walled Structures, 68: 42-49.

[24] American Society for Testing and Materials (ASTM). (1997). "Standard test methods for tension testing of metallic materials.” E 8M-97, West Conshohocken, Pa.

[25] Australian Standard (AS). (2007). "Methods for tensile testing of metals.” AS 1391-2007, Standards Association of Australia, Sydney, Australia.

[26] ABAQUS Version 6.10-1 (2010) [Computer software]. Hibbit, Karlsson \&Sorensen, Pawtucket, RI.

[27] Liu, Y and Gannon, L. (2009). "Finite element study of steel beams reinforced while under load”, Engineering Structures, 31(11): 2630 - 2642.

[28] Zhou, F and Young, Ben (2010) "Web crippling of aluminium tubes with perforated webs", Engineering Structures, 32(5): 1397-1410.

[29] Rasmussen, K. J. R., and Hancock, G. J. (1993). "Design of cold-formed stainless steel tubular members. I: Columns.” Journal of Structural Engineering, ASCE, 119(8): 2349-2367.

[30] Jandera, M., Gardner, L., and Machacek, J. (2008). "Residual stresses in cold-rolled stainless steel hollow sections.” Journal of Construction Steel Research., 64(11): 1255-1263.

[31] Mazzolani, F. M. (1994). Aluminium alloy structures, 2nd Ed., E\&FN Spon Press, London, U.K.

[32] Su, M., Young, B. and Gardner, L. (2014) "Testing and design of aluminum alloy crosssections in compression.” Journal of Structural Engineering, ASCE, 140(9), 04014047. 
Table 1. Measured specimen dimensions and material properties obtained from the tensile coupon tests

\begin{tabular}{|c|c|c|c|c|c|c|c|c|}
\hline Specimen & $\begin{array}{c}B \\
(\mathrm{~mm})\end{array}$ & $\begin{array}{c}H \\
(\mathrm{~mm})\end{array}$ & $\begin{array}{c}t \\
(\mathrm{~mm})\end{array}$ & $\begin{array}{c}E \\
(\mathrm{GPa})\end{array}$ & $\begin{array}{c}f_{y} \\
(\mathrm{MPa})\end{array}$ & $\begin{array}{c}f_{u} \\
(\mathrm{MPa})\end{array}$ & $\begin{array}{c}\varepsilon_{u} \\
(\%)\end{array}$ & $\begin{array}{c}\varepsilon_{f} \\
(\%)\end{array}$ \\
\hline$+\mathrm{H} 50 \times 95 \times 10.5 \mathrm{~B} 3$ & 49.7 & 94.7 & 10.35 & 70 & 199 & 218 & 4.7 & 11.0 \\
\hline$+\mathrm{H} 95 \times 50 \times 10.5 \mathrm{~B} 3$ & 94.6 & 49.8 & 10.30 & 70 & 199 & 218 & 4.7 & 11.0 \\
\hline$+\mathrm{H} 70 \times 120 \times 10.5 \mathrm{~B} 3$ & 69.8 & 119.9 & 10.28 & 70 & 192 & 222 & 8.5 & 11.2 \\
\hline$+\mathrm{H} 120 \times 70 \times 10.5 \mathrm{~B} 3$ & 119.9 & 69.8 & 10.32 & 70 & 192 & 222 & 8.5 & 11.2 \\
\hline$+\mathrm{H} 95 \times 95 \times 4.3 \mathrm{~B} 3$ & 95.2 & 95.1 & 4.13 & 67 & 228 & 240 & 6.0 & 6.4 \\
\hline +H95×95×4.3B3-R & 95.2 & 95.3 & 4.17 & 67 & 228 & 240 & 6.0 & 6.4 \\
\hline$+\mathrm{H} 70 \times 120 \times 10.5 \mathrm{~B} 4$ & 69.9 & 119.9 & 10.30 & 70 & 192 & 222 & 8.5 & 11.2 \\
\hline$+\mathrm{H} 120 \times 70 \times 10.5 \mathrm{~B} 4$ & 120.0 & 69.9 & 10.31 & 69 & 210 & 238 & 4.6 & 6.5 \\
\hline$+\mathrm{H} 95 \times 95 \times 4.3 \mathrm{~B} 4$ & 95.3 & 95.2 & 4.16 & 66 & 228 & 236 & 6.0 & 7.7 \\
\hline$+\mathrm{N} 50 \times 95 \times 10.5 \mathrm{~B} 4$ & 49.7 & 94.6 & 10.13 & 72 & 122 & 186 & 9.9 & 17.0 \\
\hline$+\mathrm{N} 95 \times 50 \times 10.5 \mathrm{~B} 4$ & 94.6 & 49.7 & 10.08 & 72 & 122 & 186 & 9.9 & 17.0 \\
\hline$+\mathrm{H} 50 \times 95 \times 10.5 \mathrm{~B} 5 \mathrm{I}$ & 49.9 & 94.7 & 10.33 & 70 & 199 & 218 & 4.7 & 11.0 \\
\hline$+\mathrm{H} 95 \times 50 \times 10.5 \mathrm{~B} 5 \mathrm{I}$ & 94.8 & 49.9 & 10.35 & 70 & 199 & 218 & 4.7 & 11.0 \\
\hline$+\mathrm{H} 70 \times 120 \times 10.5 \mathrm{~B} 5 \mathrm{I}$ & 69.9 & 120.0 & 10.30 & 70 & 192 & 222 & 8.5 & 11.2 \\
\hline$+\mathrm{H} 120 \times 70 \times 10.5 \mathrm{~B} 5 \mathrm{I}$ & 120.0 & 70.0 & 10.30 & 70 & 192 & 222 & 8.5 & 11.2 \\
\hline$+\mathrm{H} 95 \times 95 \times 4.3 \mathrm{~B} 5 \mathrm{I}$ & 95.3 & 95.2 & 4.17 & 66 & 228 & 236 & 6.0 & 7.7 \\
\hline$+\mathrm{H} 95 \times 95 \times 4.3 \mathrm{~B} 5 \mathrm{I}-\mathrm{R}$ & 95.2 & 95.2 & 4.14 & 67 & 228 & 240 & 6.0 & 6.4 \\
\hline$+\mathrm{N} 50 \times 95 \times 10.5 \mathrm{~B} 5 \mathrm{I}$ & 49.7 & 94.6 & 10.28 & 68 & 151 & 181 & 9.6 & 14.7 \\
\hline$+\mathrm{N} 95 \times 50 \times 10.5 \mathrm{~B} 5 \mathrm{I}$ & 94.7 & 49.7 & 10.27 & 68 & 151 & 181 & 9.6 & 14.7 \\
\hline$+\mathrm{H} 50 \times 95 \times 10.5 \mathrm{~B} 5 \mathrm{II}$ & 49.7 & 94.6 & 10.26 & 70 & 199 & 218 & 4.7 & 11.0 \\
\hline$+\mathrm{H} 70 \times 120 \times 10.5 \mathrm{~B} 5 \mathrm{II}$ & 69.9 & 120.0 & 10.26 & 70 & 192 & 222 & 8.5 & 11.2 \\
\hline +H120×70×10.5B5II & 120.0 & 69.9 & 10.33 & 70 & 192 & 222 & 8.5 & 11.2 \\
\hline +H95×95×4.3B5II & 95.3 & 95.2 & 4.17 & 67 & 228 & 240 & 6.0 & 6.4 \\
\hline +H95×95×4.3B5II-R & 95.2 & 95.2 & 4.15 & 66 & 228 & 236 & 6.0 & 7.7 \\
\hline +N95×50×10.5B5II & 94.6 & 49.7 & 10.31 & 68 & 151 & 181 & 9.6 & 14.7 \\
\hline$+\mathrm{H} 50 \times 95 \times 10.5 \mathrm{~B} 5 \mathrm{III}$ & 49.76 & 94.7 & 10.29 & 70 & 199 & 218 & 4.7 & 11.0 \\
\hline$+\mathrm{H} 70 \times 120 \times 10.5 \mathrm{~B} 5 \mathrm{III}$ & 69.94 & 120.0 & 10.25 & 69 & 210 & 238 & 4.6 & 6.5 \\
\hline$+\mathrm{H} 120 \times 70 \times 10.5 \mathrm{~B} 5 \mathrm{III}$ & 120.07 & 69.9 & 10.35 & 69 & 215 & 229 & 7.5 & 10.7 \\
\hline +H95×95×4.3B5III & 95.27 & 95.2 & 4.15 & 69 & 208 & 238 & 7.0 & 9.5 \\
\hline +H95×95×4.3B5III-R & 95.14 & 95.3 & 4.16 & 67 & 228 & 240 & 6.0 & 6.4 \\
\hline
\end{tabular}


Table 2. Comparison between simply supported bending test results and design capacities

\begin{tabular}{|c|c|c|c|c|c|c|}
\hline Specimen & $\bar{\lambda} p$ & $\begin{array}{c}M_{\text {exp }} \\
(\mathrm{kNm})\end{array}$ & $\frac{M_{\text {exp }}}{M_{A A}}$ & $\frac{M_{\text {exp }}}{M_{A S / N Z S}}$ & $\frac{M_{\exp }}{M_{E C 9}}$ & $\frac{M_{\text {exp }}}{M_{\text {csm }}}$ \\
\hline$+\mathrm{H} 50 \times 95 \times 10.5 \mathrm{~B} 3$ & 0.05 & 26.7 & 1.67 & 2.20 & 1.51 & 1.46 \\
\hline$+\mathrm{H} 95 \times 50 \times 10.5 \mathrm{~B} 3$ & 0.12 & 13.6 & 1.51 & 2.01 & 1.41 & 1.37 \\
\hline$+\mathrm{H} 70 \times 120 \times 10.5 B 3$ & 0.08 & 45.7 & 1.64 & 2.08 & 1.44 & 1.37 \\
\hline +H120×70×10.5B3 & 0.14 & 26.9 & 1.54 & 1.93 & 1.39 & 1.32 \\
\hline +H95×95×4.3B3 & 0.30 & 16.5 & 1.29 & 1.49 & 1.21 & 1.17 \\
\hline +H95×95×4.3B3-R & 0.30 & 17.1 & 1.32 & 1.53 & 1.23 & 1.19 \\
\hline$+\mathrm{H} 70 \times 120 \times 10.5 B 4$ & 0.08 & 38.2 & 1.37 & 1.74 & 1.20 & 1.14 \\
\hline$+\mathrm{H} 120 \times 70 \times 10.5 \mathrm{~B} 4$ & 0.15 & 22.0 & 1.15 & 1.45 & 1.05 & 1.00 \\
\hline$+\mathrm{H} 95 \times 95 \times 4.3 \mathrm{~B} 4$ & 0.30 & 14.9 & 1.15 & 1.33 & 1.11 & 1.06 \\
\hline$+\mathrm{N} 50 \times 95 \times 10.5 \mathrm{~B} 4$ & 0.04 & 17.6 & 1.82 & 2.40 & 1.52 & 1.45 \\
\hline$+\mathrm{N} 95 \times 50 \times 10.5 \mathrm{~B} 4$ & 0.09 & 8.4 & 1.55 & 2.06 & 1.34 & 1.27 \\
\hline Mean & & & 1.46 & 1.84 & 1.31 & 1.25 \\
\hline $\mathrm{COV}$ & & & 0.149 & 0.191 & 0.122 & 0.122 \\
\hline
\end{tabular}

Table 3. Comparison between five-point bending test results and design capacities

\begin{tabular}{|c|c|c|c|c|c|c|}
\hline Specimen & $\bar{\lambda} p$ & $\begin{array}{l}F_{\text {exp }} \\
(\mathrm{kN})\end{array}$ & $\frac{F_{\text {exp }}}{F_{A A}}$ & $\frac{F_{\text {exp }}}{F_{A S / N Z S}}$ & $\frac{F_{\text {exp }}}{F_{E C 9}}$ & $\frac{F_{\text {exp }}}{F_{\text {Csm }}}$ \\
\hline$+\mathrm{H} 50 \times 95 \times 10.5 \mathrm{~B} 5 \mathrm{I}$ & 0.02 & 128.1 & 1.93 & 2.58 & 1.74 & 1.50 \\
\hline$+\mathrm{H} 95 \times 50 \times 10.5 \mathrm{~B} 5 \mathrm{I}$ & 0.10 & 220.9 & 1.78 & 2.37 & 1.65 & 1.44 \\
\hline$+\mathrm{H} 70 \times 120 \times 10.5 \mathrm{~B} 5 \mathrm{I}$ & 0.04 & 678.4 & 1.79 & 2.27 & 1.45 & 1.33 \\
\hline$+\mathrm{H} 120 \times 70 \times 10.5 \mathrm{~B} 5 \mathrm{I}$ & 0.11 & 416.3 & 1.74 & 2.18 & 1.44 & 1.32 \\
\hline$+\mathrm{H} 95 \times 95 \times 4.3 \mathrm{~B} 5 \mathrm{I}$ & 0.26 & 250.4 & 1.46 & 1.69 & 1.33 & 1.19 \\
\hline$+\mathrm{H} 95 \times 95 \times 4.3 \mathrm{~B} 5 \mathrm{I}-\mathrm{R}$ & 0.26 & 250.6 & 1.43 & 1.65 & 1.26 & 1.14 \\
\hline$+\mathrm{N} 50 \times 95 \times 10.5 \mathrm{~B} 5 \mathrm{I}$ & 0.02 & 329.6 & 2.00 & 2.66 & 1.58 & 1.48 \\
\hline$+\mathrm{N} 95 \times 50 \times 10.5 \mathrm{~B} 5 \mathrm{I}$ & 0.09 & 171.1 & 1.84 & 2.45 & 1.51 & 1.42 \\
\hline$+\mathrm{H} 50 \times 95 \times 10.5 \mathrm{~B} 5 \mathrm{II}$ & 0.02 & 438.9 & 2.05 & 2.75 & 1.49 & 1.31 \\
\hline$+\mathrm{H} 70 \times 120 \times 10.5 \mathrm{~B} 5 \mathrm{II}$ & 0.04 & 922.7 & 2.38 & 3.02 & 1.56 & 1.46 \\
\hline +H120×70×10.5B5II & 0.11 & 530.4 & 2.19 & 2.75 & 1.48 & 1.38 \\
\hline$+\mathrm{H} 95 \times 95 \times 4.3 \mathrm{~B} 5 \mathrm{II}$ & 0.25 & 319.4 & 1.84 & 2.13 & 1.31 & 1.20 \\
\hline +H95×95×4.3B5II-R & 0.26 & 326.0 & 1.84 & 2.13 & 1.35 & 1.22 \\
\hline$+\mathrm{N} 95 \times 50 \times 10.5 \mathrm{~B} 5 \mathrm{II}$ & 0.09 & 199.1 & 2.16 & 2.88 & 1.56 & 1.37 \\
\hline$+\mathrm{H} 50 \times 95 \times 10.5 \mathrm{~B} 5 \mathrm{III}$ & 0.01 & 358.4 & 1.56 & 2.09 & 1.51 & 1.32 \\
\hline$+\mathrm{H} 70 \times 120 \times 10.5 \mathrm{~B} 5 \mathrm{III}$ & 0.02 & 708.2 & 1.62 & 2.05 & 1.53 & 1.34 \\
\hline$+\mathrm{H} 120 \times 70 \times 10.5 \mathrm{~B} 5 \mathrm{III}$ & 0.12 & 420.2 & 1.49 & 1.87 & 1.51 & 1.32 \\
\hline +H95×95×4.3B5III & 0.24 & 274.3 & 1.61 & 1.86 & 1.44 & 1.33 \\
\hline +H95×95×4.3B5III-R & 0.25 & 253.4 & 1.36 & 1.58 & 1.30 & 1.19 \\
\hline Mean & & & 1.80 & 2.27 & 1.48 & 1.33 \\
\hline $\mathrm{COV}$ & & & 0.152 & 0.185 & 0.084 & 0.077 \\
\hline
\end{tabular}


Table 4. Comparison between experimental and numerical results of simply supported beams

\begin{tabular}{lrrr}
\hline Specimen & $\begin{array}{c}M_{\text {exp }} \\
(\mathrm{kNm})\end{array}$ & $\begin{array}{c}M_{F E} \\
(\mathrm{kNm})\end{array}$ & $\begin{array}{c}M_{\text {exp }} \\
M_{F E}\end{array}$ \\
\hline$+\mathrm{H} 50 \times 95 \times 10.5 \mathrm{~B} 3$ & 26.7 & 24.7 & 1.08 \\
$+\mathrm{H} 95 \times 50 \times 10.5 \mathrm{~B} 3$ & 13.6 & 13.5 & 1.01 \\
$+\mathrm{H} 70 \times 120 \times 10.5 \mathrm{~B} 3$ & 45.7 & 43.1 & 1.06 \\
$+\mathrm{H} 120 \times 70 \times 10.5 \mathrm{~B} 3$ & 26.9 & 26.7 & 1.00 \\
$+\mathrm{H} 95 \times 95 \times 4.3 \mathrm{~B} 3$ & 16.5 & 16.4 & 1.00 \\
$+\mathrm{H} 95 \times 95 \times 4.3 \mathrm{~B} 3-\mathrm{R}$ & 17.1 & 16.8 & 1.02 \\
$+\mathrm{H} 70 \times 120 \times 10.5 \mathrm{~B} 4$ & 38.2 & 37.8 & 1.01 \\
$+\mathrm{H} 120 \times 70 \times 10.5 \mathrm{~B} 4$ & 22.0 & 21.4 & 1.03 \\
$+\mathrm{H} 95 \times 95 \times 4.3 \mathrm{~B} 4$ & 14.9 & 14.3 & 1.04 \\
$+\mathrm{N} 50 \times 95 \times 10.5 \mathrm{~B} 4$ & 17.6 & 18.7 & 0.94 \\
$+\mathrm{N} 95 \times 50 \times 10.5 \mathrm{~B} 4$ & 8.4 & 7.8 & 1.08 \\
\hline & & Mean & 1.02 \\
& & $\mathrm{COV}$ & 0.039 \\
\hline
\end{tabular}

Table 5. Comparison between experimental and numerical results of continuous beams

\begin{tabular}{|c|c|c|c|}
\hline Specimen & $\begin{array}{l}F_{\text {exp }} \\
(\mathrm{kN})\end{array}$ & $\begin{array}{c}F_{F E} \\
(\mathrm{kN})\end{array}$ & $\frac{F_{\text {exp }}}{F_{F E}}$ \\
\hline$+\mathrm{H} 50 \times 95 \times 10.5 \mathrm{~B} 5 \mathrm{I}$ & 423.8 & 377.8 & 1.12 \\
\hline$+\mathrm{H} 95 \times 50 \times 10.5 \mathrm{~B} 5 \mathrm{I}$ & 220.9 & 212.1 & 1.04 \\
\hline$+\mathrm{H} 70 \times 120 \times 10.5 \mathrm{~B} 5 \mathrm{I}$ & 678.4 & 680.4 & 1.00 \\
\hline$+\mathrm{H} 120 \times 70 \times 10.5 \mathrm{~B} 5 \mathrm{I}$ & 416.3 & 415.0 & 1.00 \\
\hline$+\mathrm{H} 95 \times 95 \times 4.3 \mathrm{~B} 5 \mathrm{I}$ & 250.4 & 239.1 & 1.05 \\
\hline$+\mathrm{H} 95 \times 95 \times 4.3 \mathrm{~B} 5 \mathrm{I}-\mathrm{R}$ & 250.6 & 244.9 & 1.02 \\
\hline$+\mathrm{N} 50 \times 95 \times 10.5 \mathrm{~B} 5 \mathrm{I}$ & 329.6 & 328.7 & 1.00 \\
\hline$+\mathrm{N} 95 \times 50 \times 10.5 \mathrm{~B} 5 \mathrm{I}$ & 171.1 & 178.4 & 0.96 \\
\hline$+\mathrm{H} 50 \times 95 \times 10.5 \mathrm{~B} 5 \mathrm{II}$ & 438.9 & 431.5 & 1.02 \\
\hline$+\mathrm{H} 70 \times 120 \times 10.5 \mathrm{~B} 5 \mathrm{II}$ & 922.7 & 871.5 & 1.05 \\
\hline$+\mathrm{H} 120 \times 70 \times 10.5 \mathrm{~B} 5 \mathrm{II}$ & 530.4 & 535.3 & 1.00 \\
\hline +H95×95×4.3B5II & 319.4 & 326.7 & 0.98 \\
\hline$+\mathrm{H} 95 \times 95 \times 4.3 \mathrm{~B} 5 \mathrm{II}-\mathrm{R}$ & 326.0 & 310.1 & 1.05 \\
\hline$+\mathrm{N} 95 \times 50 \times 10.5 \mathrm{~B} 5 \mathrm{II}$ & 199.1 & 218.1 & 0.91 \\
\hline$+\mathrm{H} 50 \times 95 \times 10.5 \mathrm{~B} 5 \mathrm{III}$ & 358.4 & 317.3 & 1.13 \\
\hline$+\mathrm{H} 70 \times 120 \times 10.5$ B5III & 708.2 & 655.7 & 1.08 \\
\hline +H120×70×10.5B5III & 420.2 & 402.0 & 1.04 \\
\hline +H95×95×4.3B5III & 274.3 & 253.3 & 1.08 \\
\hline \multirow[t]{3}{*}{ +H95×95×4.3B5III-R } & 253.4 & 232.5 & 1.09 \\
\hline & & Mean & 1.03 \\
\hline & & $\mathrm{COV}$ & 0.052 \\
\hline
\end{tabular}


Table 6. Ultimate loads of simulated simply supported beams generated from the parametric studies

\begin{tabular}{|c|c|c|c|}
\hline Specimen & $\begin{array}{c}F_{F E} \\
(\mathrm{kN})\end{array}$ & Specimen & $\begin{array}{l}F_{F E} \\
(\mathrm{kN})\end{array}$ \\
\hline +H180×180×9.0B3 & 120.3 & $+\mathrm{H} 180 \times 180 \times 9.0 \mathrm{~B} 4$ & 116.6 \\
\hline$+\mathrm{H} 180 \times 180 \times 6.0 \mathrm{~B} 3$ & 78.4 & $+\mathrm{H} 180 \times 180 \times 6.0 \mathrm{~B} 4$ & 75.7 \\
\hline$+\mathrm{H} 180 \times 180 \times 3.5 \mathrm{~B} 3$ & 42.2 & $+\mathrm{H} 180 \times 180 \times 3.5 \mathrm{~B} 4$ & 40.6 \\
\hline$+\mathrm{H} 160 \times 200 \times 9.0 \mathrm{~B} 3$ & 131.6 & $+\mathrm{H} 160 \times 200 \times 9.0 \mathrm{~B} 4$ & 123.2 \\
\hline$+\mathrm{H} 160 \times 200 \times 6.0 \mathrm{~B} 3$ & 90.6 & $+\mathrm{H} 160 \times 200 \times 6.0 \mathrm{~B} 4$ & 84.4 \\
\hline$+\mathrm{H} 160 \times 200 \times 3.5 B 3$ & 50.3 & $+\mathrm{H} 160 \times 200 \times 3.5 B 4$ & 46.4 \\
\hline$+\mathrm{H} 140 \times 100 \times 6.5 \mathrm{~B} 3$ & 35.9 & $+\mathrm{H} 140 \times 100 \times 6.5 \mathrm{~B} 4$ & 30.4 \\
\hline$+\mathrm{H} 140 \times 100 \times 5.0 \mathrm{~B} 3$ & 28.0 & $+\mathrm{H} 140 \times 100 \times 5.0 \mathrm{~B} 4$ & 23.2 \\
\hline$+\mathrm{H} 140 \times 100 \times 2.5 \mathrm{~B} 3$ & 13.5 & $+\mathrm{H} 140 \times 100 \times 2.5 \mathrm{~B} 4$ & 12.0 \\
\hline$+\mathrm{H} 130 \times 50 \times 6.5 \mathrm{~B} 3$ & 12.6 & $+\mathrm{H} 130 \times 50 \times 6.5 \mathrm{~B} 4$ & 11.0 \\
\hline$+\mathrm{H} 130 \times 50 \times 5.0 \mathrm{~B} 3$ & 10.4 & $+\mathrm{H} 130 \times 50 \times 5.0 \mathrm{~B} 4$ & 8.6 \\
\hline$+\mathrm{H} 130 \times 50 \times 2.5 \mathrm{~B} 3$ & 5.1 & $+\mathrm{H} 130 \times 50 \times 2.5 \mathrm{~B} 4$ & 4.5 \\
\hline$+\mathrm{H} 50 \times 130 \times 6.5 \mathrm{~B} 3$ & 31.8 & $+\mathrm{H} 50 \times 130 \times 6.5 \mathrm{~B} 4$ & 27.5 \\
\hline$+\mathrm{H} 50 \times 130 \times 5.0 \mathrm{~B} 3$ & 25.0 & $+\mathrm{H} 50 \times 130 \times 5.0 \mathrm{~B} 4$ & 21.5 \\
\hline$+\mathrm{H} 50 \times 130 \times 2.5 \mathrm{~B} 3$ & 11.9 & $+\mathrm{H} 50 \times 130 \times 2.5 \mathrm{~B} 4$ & 10.7 \\
\hline$+\mathrm{N} 180 \times 180 \times 9.0 \mathrm{~B} 3$ & 84.2 & $+\mathrm{N} 180 \times 180 \times 9.0 \mathrm{~B} 4$ & 80.1 \\
\hline$+\mathrm{N} 180 \times 180 \times 6.0 \mathrm{~B} 3$ & 51.7 & $+\mathrm{N} 180 \times 180 \times 6.0 \mathrm{~B} 4$ & 49.0 \\
\hline$+\mathrm{N} 180 \times 180 \times 3.5 \mathrm{~B} 3$ & 25.6 & $+\mathrm{N} 180 \times 180 \times 3.5 \mathrm{~B} 4$ & 22.9 \\
\hline$+\mathrm{N} 160 \times 200 \times 9.0 \mathrm{~B} 3$ & 93.3 & $+\mathrm{N} 160 \times 200 \times 9.0 \mathrm{~B} 4$ & 78.9 \\
\hline$+\mathrm{N} 160 \times 200 \times 6.0 \mathrm{~B} 3$ & 65.0 & $+\mathrm{N} 160 \times 200 \times 6.0 \mathrm{~B} 4$ & 55.0 \\
\hline$+\mathrm{N} 160 \times 200 \times 3.5 \mathrm{~B} 3$ & 31.2 & $+\mathrm{N} 160 \times 200 \times 3.5 \mathrm{~B} 4$ & 28.4 \\
\hline$+\mathrm{N} 140 \times 100 \times 6.5 \mathrm{~B} 3$ & 26.8 & $+\mathrm{N} 140 \times 100 \times 6.5 \mathrm{~B} 4$ & 19.2 \\
\hline$+\mathrm{N} 140 \times 100 \times 5.0 \mathrm{~B} 3$ & 20.4 & $+\mathrm{N} 140 \times 100 \times 5.0 \mathrm{~B} 4$ & 14.5 \\
\hline$+\mathrm{N} 140 \times 100 \times 2.5 \mathrm{~B} 3$ & 8.1 & $+\mathrm{N} 140 \times 100 \times 2.5 \mathrm{~B} 4$ & 6.9 \\
\hline$+\mathrm{N} 130 \times 50 \times 6.5 \mathrm{~B} 3$ & 8.5 & $+\mathrm{N} 130 \times 50 \times 6.5 \mathrm{~B} 4$ & 6.5 \\
\hline$+\mathrm{N} 130 \times 50 \times 5.0 \mathrm{~B} 3$ & 6.5 & $+\mathrm{N} 130 \times 50 \times 5.0 \mathrm{~B} 4$ & 5.1 \\
\hline$+\mathrm{N} 130 \times 50 \times 2.5 \mathrm{~B} 3$ & 3.3 & $+\mathrm{N} 130 \times 50 \times 2.5 \mathrm{~B} 4$ & 2.7 \\
\hline$+\mathrm{N} 50 \times 130 \times 6.5 \mathrm{~B} 3$ & 23.6 & $+\mathrm{N} 50 \times 130 \times 6.5 \mathrm{~B} 4$ & 18.5 \\
\hline$+\mathrm{N} 50 \times 130 \times 5.0 \mathrm{~B} 3$ & 18.3 & $+\mathrm{N} 50 \times 130 \times 5.0 \mathrm{~B} 4$ & 14.6 \\
\hline$+\mathrm{N} 50 \times 130 \times 2.5 \mathrm{~B} 3$ & 7.9 & $+\mathrm{N} 50 \times 130 \times 2.5 \mathrm{~B} 4$ & 7.2 \\
\hline
\end{tabular}


Table 7. Ultimate loads of simulated continuous beams generated from the parametric studies

\begin{tabular}{|c|c|c|c|c|c|}
\hline Specimen & $\begin{array}{l}F_{F E} \\
(\mathrm{kN})\end{array}$ & Specimen & $\begin{array}{l}F_{F E} \\
(\mathrm{kN})\end{array}$ & Specimen & $\begin{array}{l}F_{F E} \\
(\mathrm{kN})\end{array}$ \\
\hline$+\mathrm{H} 180 \times 180 \times 9.0 \mathrm{~B} 5 \mathrm{I}$ & 50.0 & +H180×180×9.0 B5II & 1030.0 & +H180×180×9.0 B5III & 797.4 \\
\hline$+\mathrm{H} 180 \times 180 \times 6.0 \mathrm{~B} 5 \mathrm{I}$ & 561.1 & +H180×180×6.0 B5II & 634.5 & +H180×180×6.0 B5III & 512.7 \\
\hline +H180×180×3.5 B5I & 307.0 & +H180×180×3.5 B5II & 318.1 & +H180×180×3.5 B5III & 262.2 \\
\hline$+\mathrm{H} 160 \times 200 \times 9.0 \mathrm{~B} 5 \mathrm{I}$ & 930.1 & +H160×200×9.0 B5II & 1061.0 & $+\mathrm{H} 160 \times 200 \times 9.0 \mathrm{~B} 5 \mathrm{III}$ & 863.5 \\
\hline$+\mathrm{H} 160 \times 200 \times 6.0 \mathrm{~B} 5 \mathrm{I}$ & 604.9 & +H160×200×6.0 B5II & 641.3 & +H160×200×6.0 B5III & 556.0 \\
\hline +H160×200×3.5 B5I & 309.7 & +H160×200×3.5 B5II & 307.8 & +H160×200×3.5 B5III & 262.7 \\
\hline$+\mathrm{H} 140 \times 100 \times 6.5 \mathrm{~B} 5 \mathrm{I}$ & 340.5 & $+\mathrm{H} 140 \times 100 \times 6.5 \mathrm{~B} 5 \mathrm{II}$ & 451.4 & $+\mathrm{H} 140 \times 100 \times 6.5 \mathrm{~B} 5 \mathrm{III}$ & 344.2 \\
\hline$+\mathrm{H} 140 \times 100 \times 5.0 \mathrm{~B} 5 \mathrm{I}$ & 260.0 & $+\mathrm{H} 140 \times 100 \times 5.0 \mathrm{~B} 5 \mathrm{II}$ & 331.1 & $+\mathrm{H} 140 \times 100 \times 5.0 \mathrm{~B} 5 \mathrm{III}$ & 251.0 \\
\hline$+\mathrm{H} 140 \times 100 \times 2.5 \mathrm{~B} 5 \mathrm{I}$ & 119.9 & $+\mathrm{H} 140 \times 100 \times 2.5 \mathrm{~B} 5 \mathrm{II}$ & 158.9 & $+\mathrm{H} 140 \times 100 \times 2.5 \mathrm{~B} 5 \mathrm{III}$ & 120.7 \\
\hline$+\mathrm{H} 130 \times 50 \times 6.5 \mathrm{~B} 5 \mathrm{I}$ & 201.7 & $+\mathrm{H} 130 \times 50 \times 6.5 \mathrm{~B} 5 \mathrm{II}$ & 265.5 & $+\mathrm{H} 130 \times 50 \times 6.5 \mathrm{~B} 5 \mathrm{III}$ & 192.1 \\
\hline$+\mathrm{H} 130 \times 50 \times 5.0 \mathrm{~B} 5 \mathrm{I}$ & 157.1 & $+\mathrm{H} 130 \times 50 \times 5.0 \mathrm{~B} 5 \mathrm{II}$ & 206.7 & +H130×50×5.0 B5III & 149.7 \\
\hline$+\mathrm{H} 130 \times 50 \times 2.5 \mathrm{~B} 5 \mathrm{I}$ & 77.4 & $+\mathrm{H} 130 \times 50 \times 2.5 \mathrm{~B} 5 \mathrm{II}$ & 100.3 & +H130×50×2.5 B5III & 72.5 \\
\hline$+\mathrm{H} 50 \times 130 \times 6.5 \mathrm{~B} 5 \mathrm{I}$ & 463.5 & $+\mathrm{H} 50 \times 130 \times 6.5 \mathrm{~B} 5 \mathrm{II}$ & 627.2 & $+\mathrm{H} 50 \times 130 \times 6.5 \mathrm{~B} 5 \mathrm{III}$ & 485.0 \\
\hline$+\mathrm{H} 50 \times 130 \times 5.0 \mathrm{~B} 5 \mathrm{I}$ & 344.2 & $+\mathrm{H} 50 \times 130 \times 5.0 \mathrm{~B} 5 \mathrm{II}$ & 452.8 & $+\mathrm{H} 50 \times 130 \times 5.0 \mathrm{~B} 5 \mathrm{III}$ & 364.8 \\
\hline$+\mathrm{H} 50 \times 130 \times 2.5 \mathrm{~B} 5 \mathrm{I}$ & 159.8 & $+\mathrm{H} 50 \times 130 \times 2.5 \mathrm{~B} 5 \mathrm{II}$ & 197.0 & +H50×130×2.5 B5III & 156.6 \\
\hline$+\mathrm{N} 180 \times 180 \times 9.0 \mathrm{~B} 5 \mathrm{I}$ & 529.8 & $+\mathrm{N} 180 \times 180 \times 9.0 \mathrm{~B} 5 \mathrm{II}$ & 644.4 & $+\mathrm{N} 180 \times 180 \times 9.0 \mathrm{~B} 5 \mathrm{III}$ & 499.2 \\
\hline$+\mathrm{N} 180 \times 180 \times 6.0 \mathrm{~B} 5 \mathrm{I}$ & 325.3 & +N180×180×6.0 B5II & 373.1 & $+\mathrm{N} 180 \times 180 \times 6.0 \mathrm{~B} 5 \mathrm{III}$ & 295.0 \\
\hline$+\mathrm{N} 180 \times 180 \times 3.5 \mathrm{~B} 5 \mathrm{I}$ & 154.1 & $+\mathrm{N} 180 \times 180 \times 3.5 \mathrm{~B} 5 \mathrm{II}$ & 177.4 & $+\mathrm{N} 180 \times 180 \times 3.5 \mathrm{~B} 5 \mathrm{III}$ & 164.7 \\
\hline$+\mathrm{N} 160 \times 200 \times 9.0 \mathrm{~B} 5 \mathrm{I}$ & 56 & $+\mathrm{N} 160 \times 200 \times 9.0 \mathrm{~B} 5 \mathrm{II}$ & 2 & $+\mathrm{N} 160 \times 200 \times 9.0 \mathrm{~B} 5 \mathrm{III}$ & 4.9 \\
\hline$+\mathrm{N} 160 \times 200 \times 6.0 \mathrm{~B} 5 \mathrm{I}$ & 347.4 & $+\mathrm{N} 160 \times 200 \times 6.0 \mathrm{~B} 5 \mathrm{II}$ & 3 & $+\mathrm{N} 160 \times 200 \times 6.0 \mathrm{~B} 5 \mathrm{III}$ & 342.0 \\
\hline$+\mathrm{N} 160 \times 200 \times 3.5 \mathrm{~B} 5 \mathrm{I}$ & 144.6 & $+\mathrm{N} 160 \times 200 \times 3.5 \mathrm{~B} 5 \mathrm{II}$ & 174.6 & $+\mathrm{N} 160 \times 200 \times 3.5 \mathrm{~B} 5 \mathrm{III}$ & 170.5 \\
\hline$+\mathrm{N} 140 \times 100 \times 6.5 \mathrm{~B} 5 \mathrm{I}$ & 238.3 & $+\mathrm{N} 140 \times 100 \times 6.5 \mathrm{~B} 5 \mathrm{II}$ & S12.0 & $+\mathrm{N} 140 \times 100 \times 6.5 \mathrm{~B} 5 \mathrm{III}$ & 245.6 \\
\hline$+\mathrm{N} 140 \times 100 \times 5.0 \mathrm{~B} 5 \mathrm{I}$ & 177 & $+\mathrm{N} 140 \times 100 \times 5.0 \mathrm{~B} 5 \mathrm{II}$ & 2 & $+\mathrm{N} 140 \times 100 \times 5.0 \mathrm{~B} 5 \mathrm{III}$ & 170.2 \\
\hline$+\mathrm{N} 140 \times 100 \times 2.5 \mathrm{~B} 5 \mathrm{I}$ & $y$ & $+\mathrm{N} 140 \times 100 \times 2.5 \mathrm{~B} 5 \mathrm{II}$ & 10 & $+\mathrm{N} 140 \times 100 \times 2.5 \mathrm{~B} 5 \mathrm{III}$ & 0.8 \\
\hline +N130×50×6.5 B5I & 141.1 & $+\mathrm{N} 130 \times 50 \times 6.5 \mathrm{~B} 5 \mathrm{II}$ & 17 & $+\mathrm{N} 130 \times 50 \times 6.5 \mathrm{~B} 5 \mathrm{III}$ & 132.4 \\
\hline$+\mathrm{N} 130 \times 50 \times 5.0 \mathrm{~B} 5 \mathrm{I}$ & 108.0 & $+\mathrm{N} 130 \times 50 \times 5.0 \mathrm{~B} 5 \mathrm{II}$ & 138.0 & $+\mathrm{N} 130 \times 50 \times 5.0 \mathrm{~B} 5 \mathrm{III}$ & 103.1 \\
\hline$+\mathrm{N} 130 \times 50 \times 2.5 \mathrm{~B} 5 \mathrm{I}$ & 50.9 & $+\mathrm{N} 130 \times 50 \times 2.5 \mathrm{~B} 5 \mathrm{II}$ & 65.8 & $+\mathrm{N} 130 \times 50 \times 2.5 \mathrm{~B} 5 \mathrm{III}$ & 51.3 \\
\hline$+\mathrm{N} 50 \times 130 \times 6.5 \mathrm{~B} 5 \mathrm{I}$ & 340.1 & $+\mathrm{N} 50 \times 130 \times 6.5 \mathrm{~B} 5 \mathrm{II}$ & 450.4 & $+\mathrm{N} 50 \times 130 \times 6.5 \mathrm{~B} 5 \mathrm{III}$ & 358.6 \\
\hline$+\mathrm{N} 50 \times 130 \times 5.0 \mathrm{~B} 5 \mathrm{I}$ & 233.1 & $+\mathrm{N} 50 \times 130 \times 5.0 \mathrm{~B} 5 \mathrm{II}$ & 2 & $+\mathrm{N} 50 \times 130 \times 5.0 \mathrm{~B} 5 \mathrm{III}$ & 269.4 \\
\hline$+\mathrm{N} 50 \times 130 \times 2.5 \mathrm{~B} 5 \mathrm{I}$ & 104.2 & $+\mathrm{N} 50 \times 130 \times 2.5 \mathrm{~B} 5 \mathrm{II}$ & 120.9 & +N50×130×2.5 B5III & 104.7 \\
\hline
\end{tabular}


Table 8. Summary of comparisons between bending test and numerical results with design strengths

\begin{tabular}{|c|c|c|c|c|c|c|c|c|}
\hline & \multicolumn{4}{|c|}{ Simply Supported Beams } & \multicolumn{4}{|c|}{ Continuous Beams } \\
\hline & $M_{u}$ & $M_{u}$ & $M_{u}$ & $M_{u}$ & $F_{u}$ & $F_{u}$ & $F_{u}$ & $F_{u}$ \\
\hline & $\overline{M_{A A}}$ & $\overline{M_{A S} / N Z S}$ & $\overline{M_{E C 9}}$ & $\overline{M_{C S m}}$ & $\overline{F_{A A}}$ & $\overline{F_{A S} / N Z S}$ & $\overline{F_{E C 9}}$ & $\overline{F_{C S m}}$ \\
\hline $\begin{array}{l}\text { Number of } \\
\text { specimens }\end{array}$ & \multicolumn{4}{|c|}{71} & \multicolumn{4}{|c|}{109} \\
\hline Mean & 1.40 & 1.66 & 1.27 & 1.18 & 1.70 & 2.02 & 1.37 & 1.25 \\
\hline $\mathrm{COV}$ & 0.207 & 0.233 & 0.150 & 0.153 & 0.251 & 0.276 & 0.178 & 0.165 \\
\hline
\end{tabular}




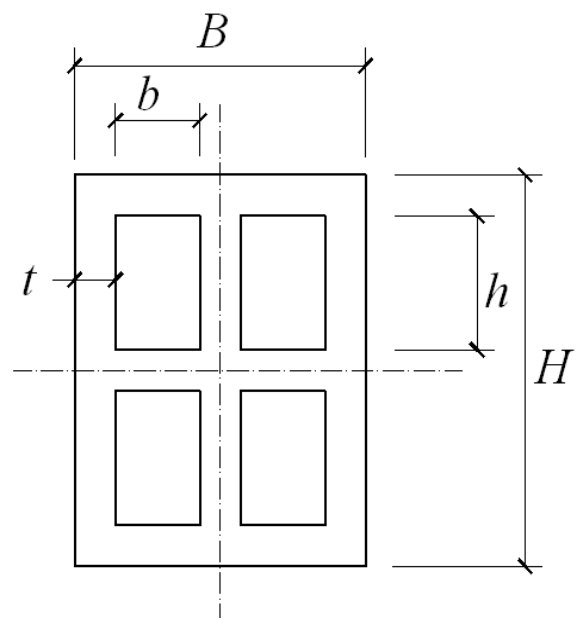

Figure 1. Definition of symbols for SHS/RHS with internal stiffeners having all elements of same thickness 


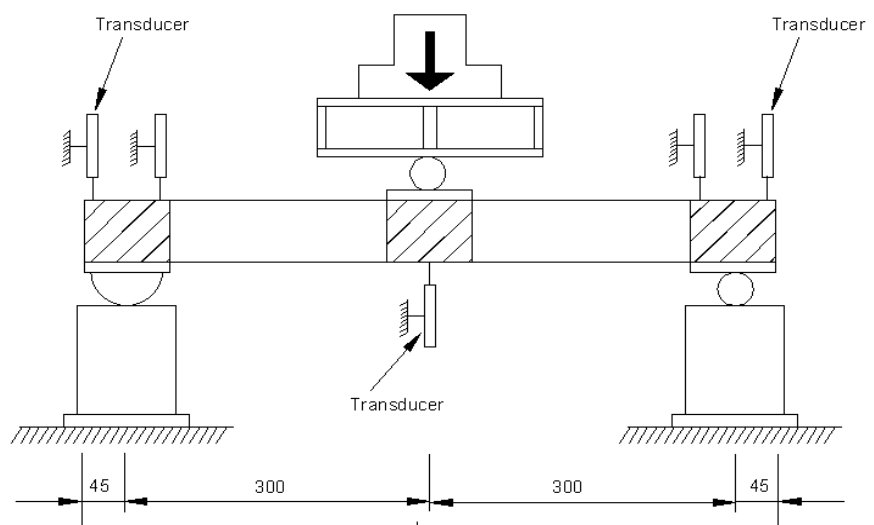

Figure 2. Schematic illustration of three-point bending test configuration (dimensions in mm)

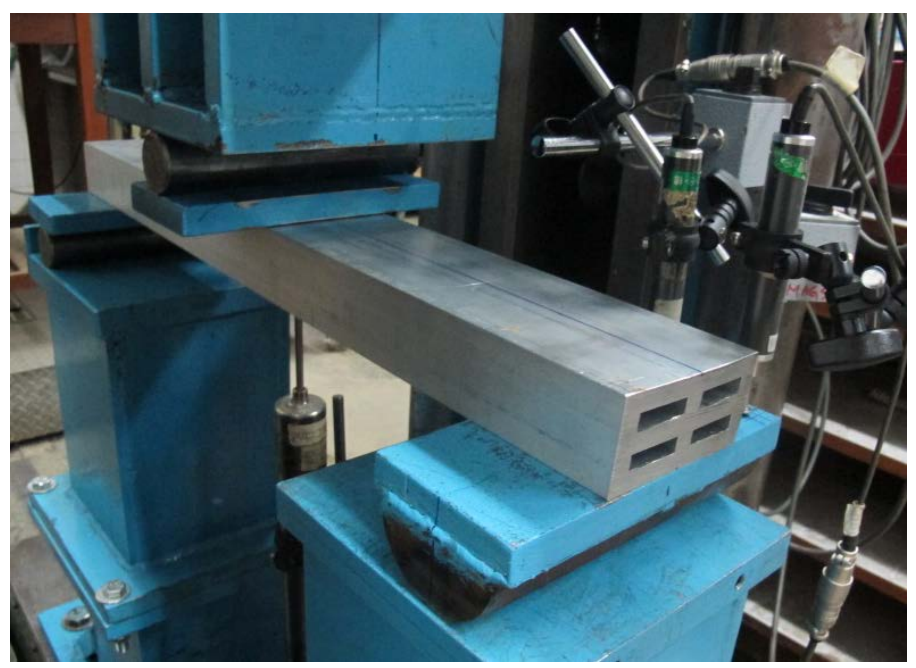

Figure 3. Experimental setup for three-point bending test 


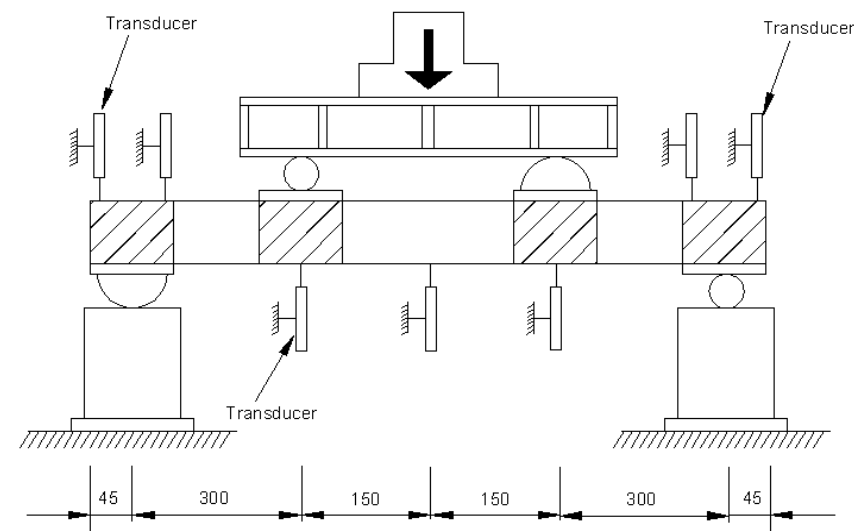

Figure 4. Schematic illustration of four-point bending test configuration (dimensions in mm)

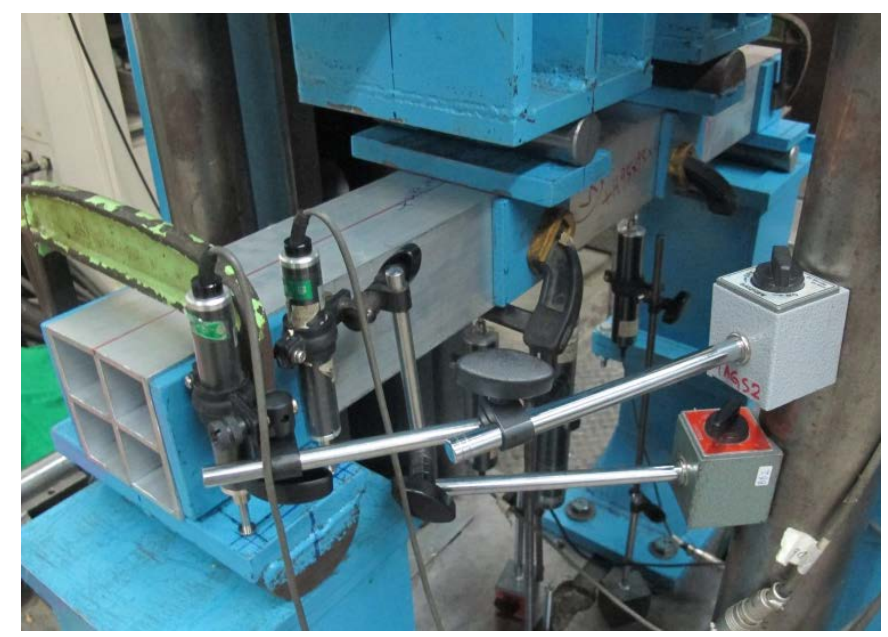

Figure 5. Experimental setup for four-point bending test 


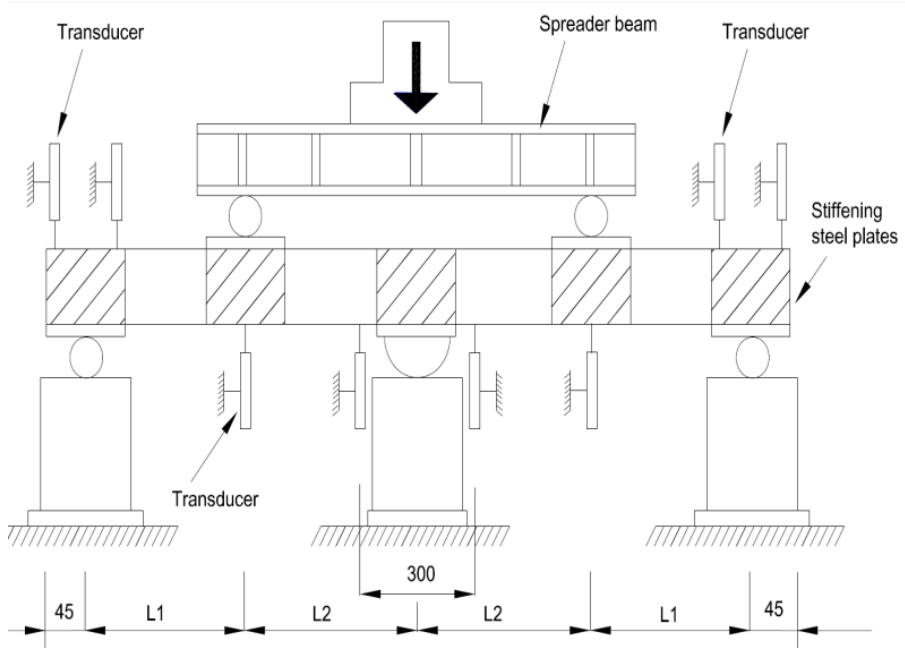

Figure 6. Schematic illustration of five-point bending configuration (dimensions in mm)

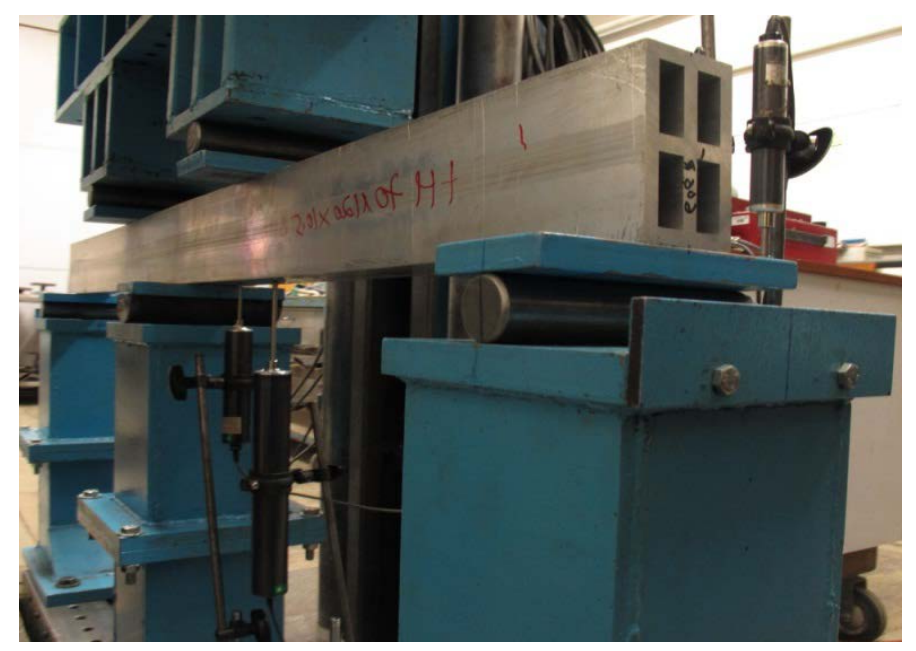

Figure 7. Experimental setup for five-point bending test 


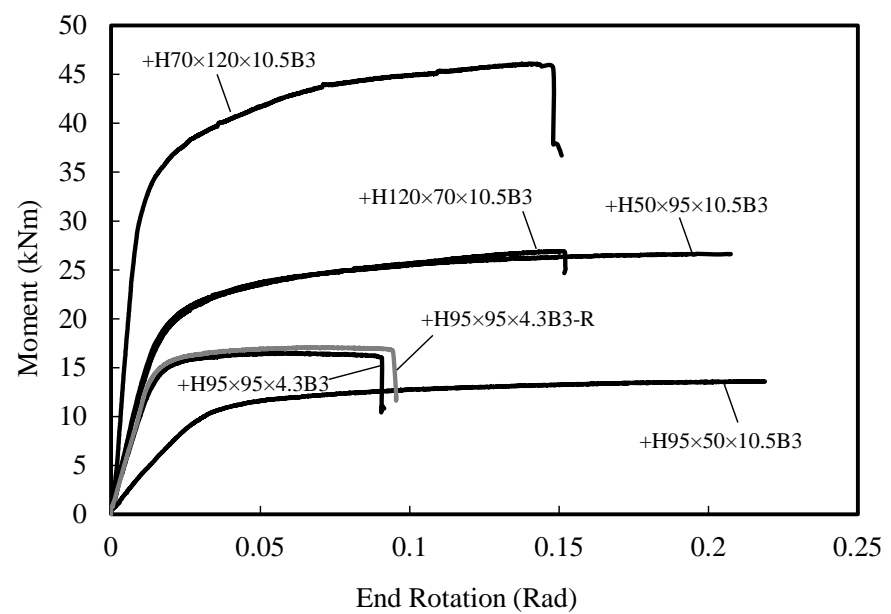

Figure 8. Moment-end rotation curves obtained from three-point bending tests
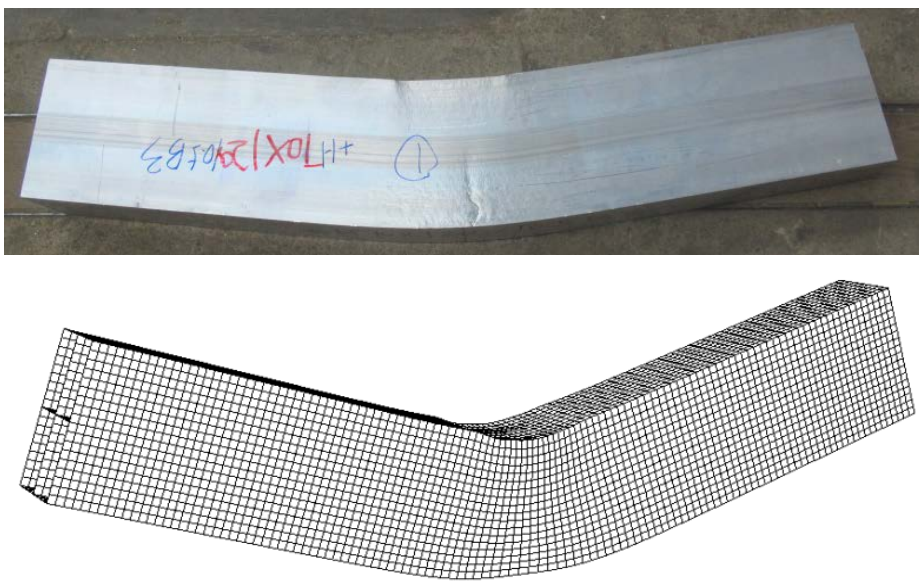

Figure 9. Tested and numerical three-point bending beams $(+\mathrm{H} 70 \times 120 \times 10.5 \mathrm{~B} 3)$ 


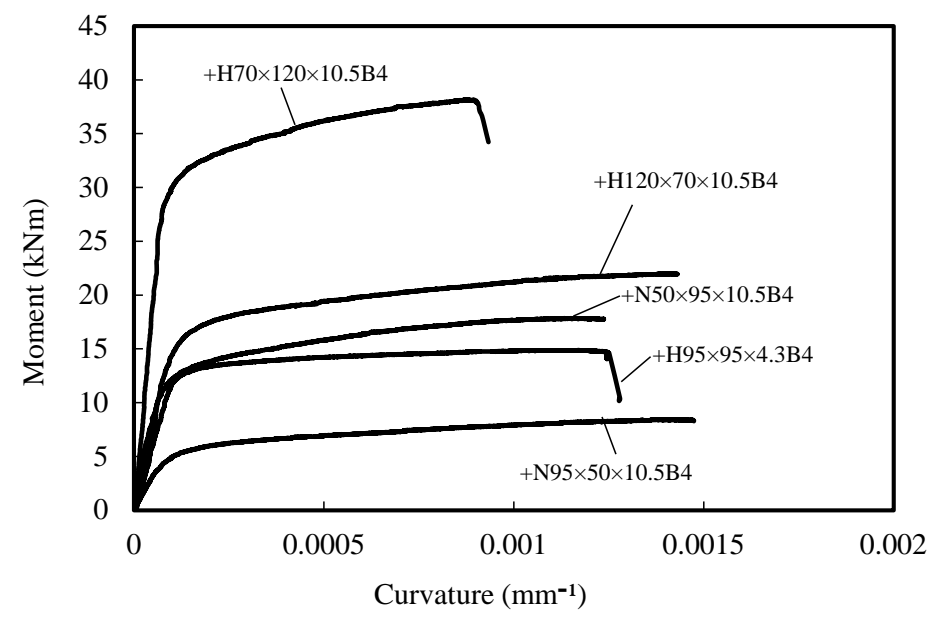

Figure 10. Moment-curvature curves obtained from four-point bending tests
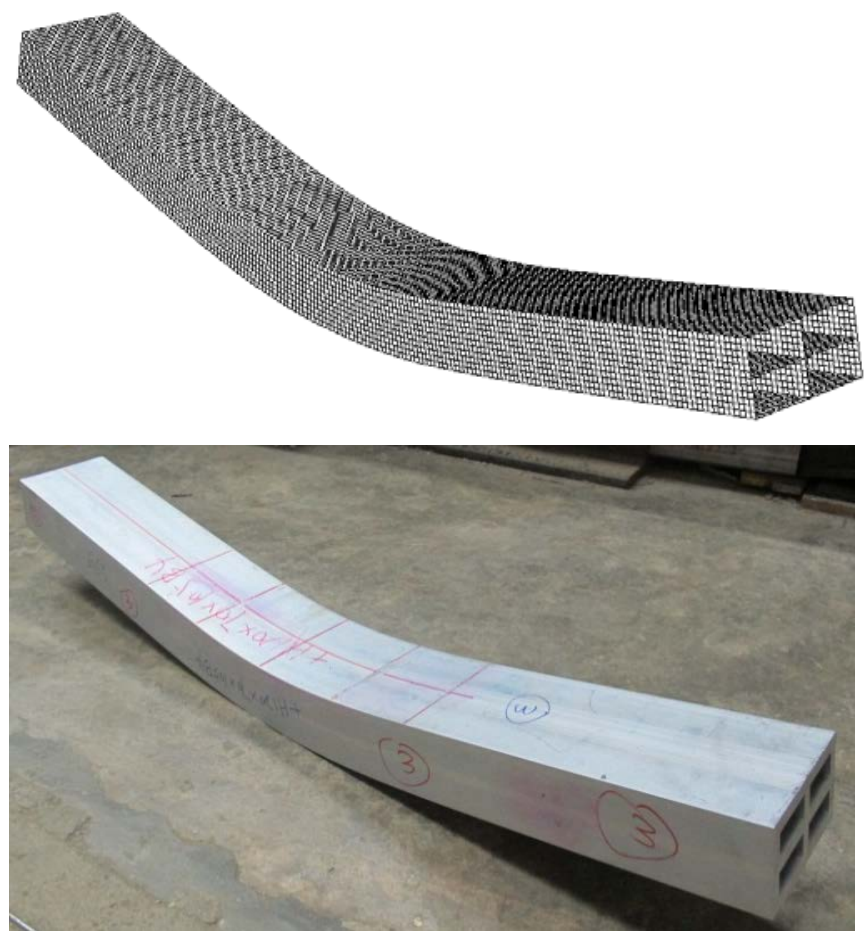

Figure 11. Tested and numerical four-point bending beams $(+N 95 \times 50 \times 10.5 B 4)$ 


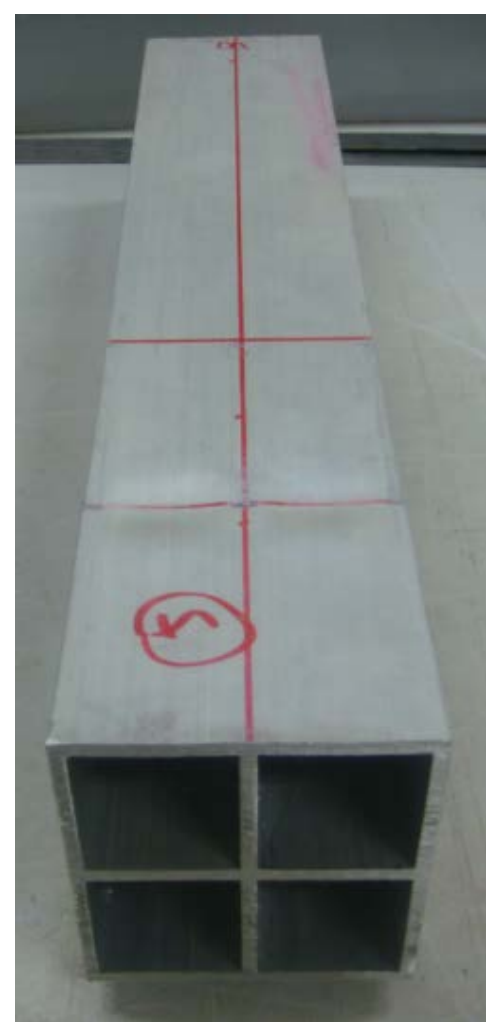

Figure 12. Tested four-point bending beams after cutting in the mid-span $(+H 95 \times 595 \times 4.3 B 4)$ 


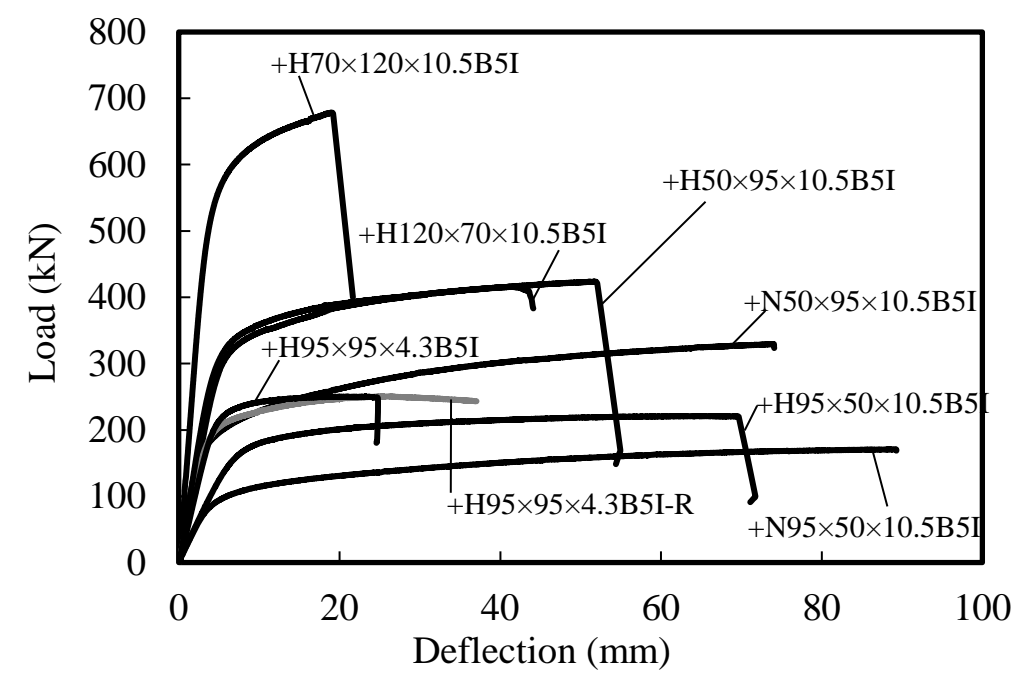

(a) Configuration I

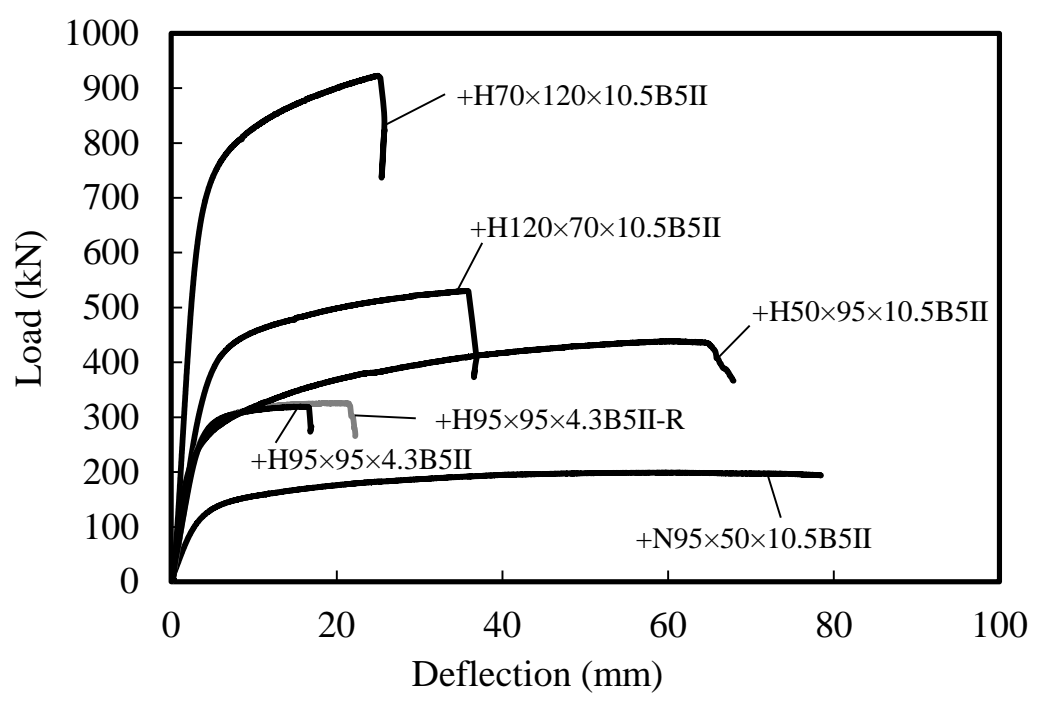

(b) Configuration II

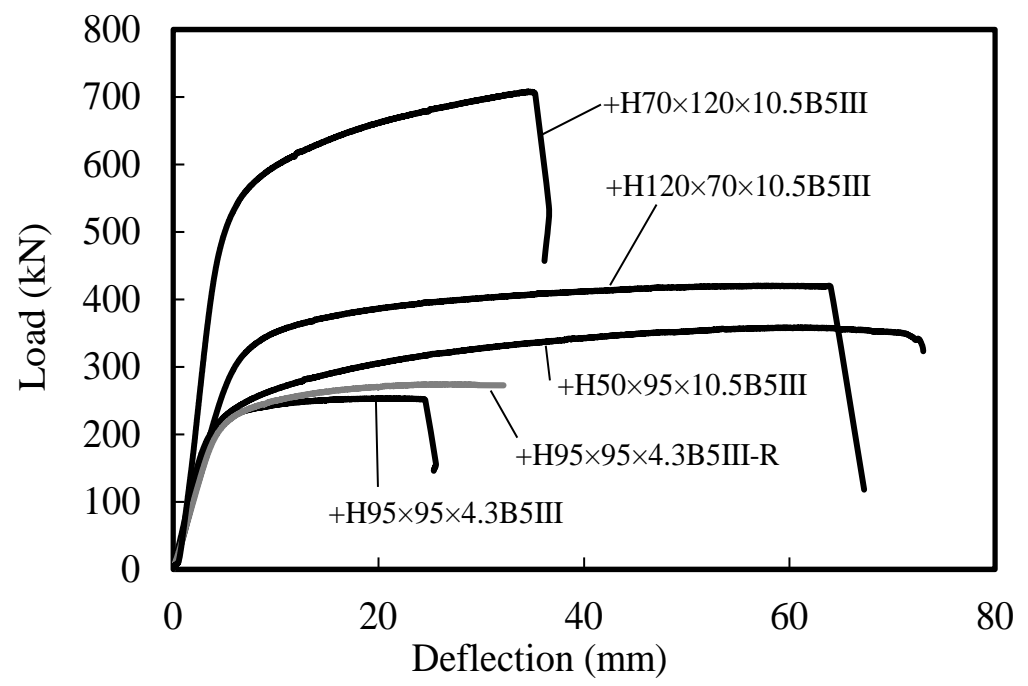

(c) Configuration III

Figure 13. Load-deflection curves obtained from five-point bending tests 


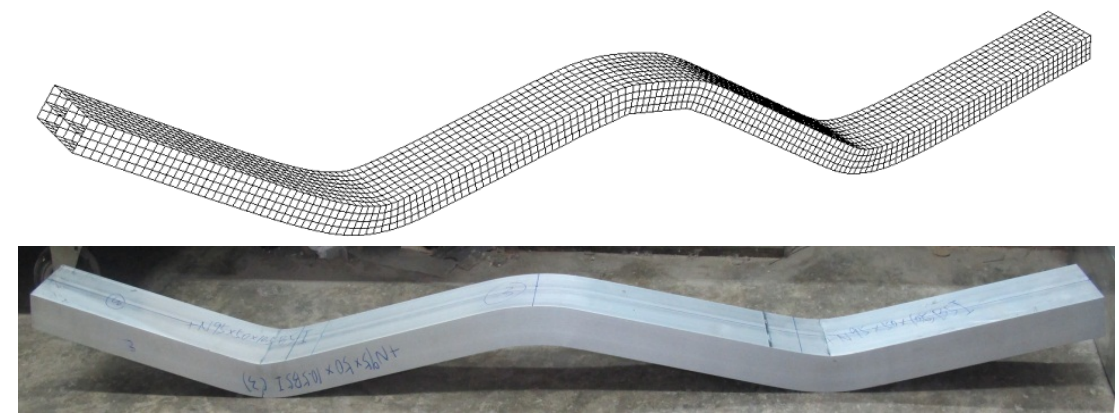

Figure 14. Tested and numerical five-point bending beams $(+$ N95 $\times 50 \times 10.5 \mathrm{~B} 5 \mathrm{I})$

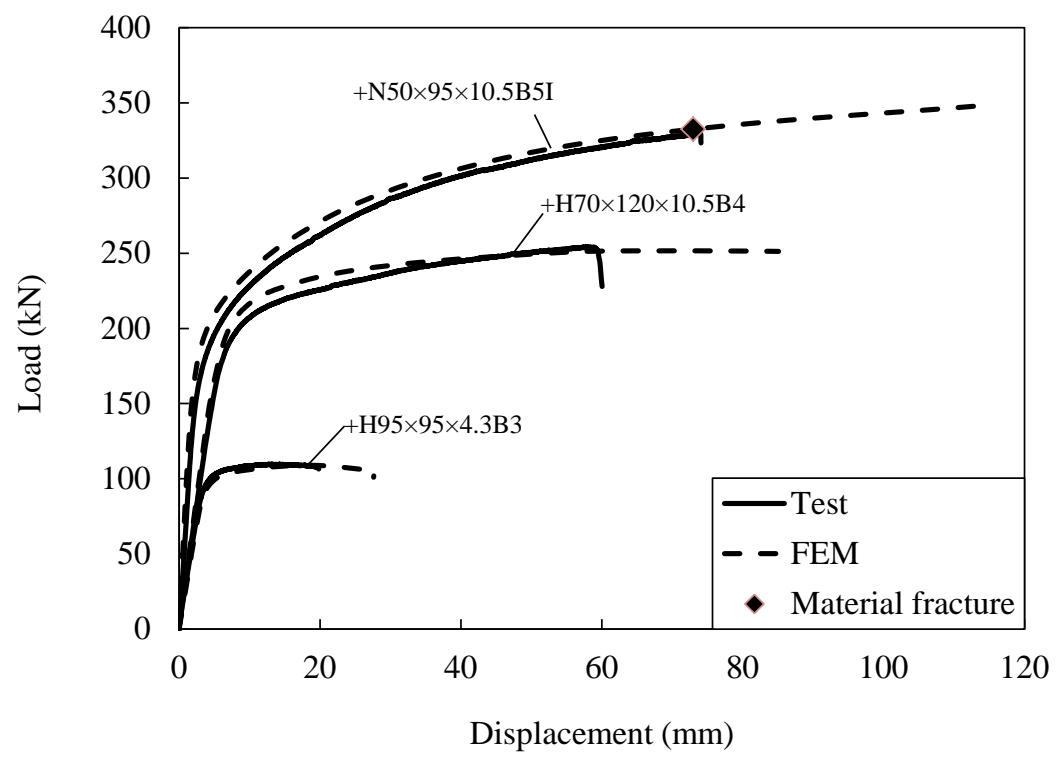

Figure 15. Experimental and numerical load-displacement curves for specimen 


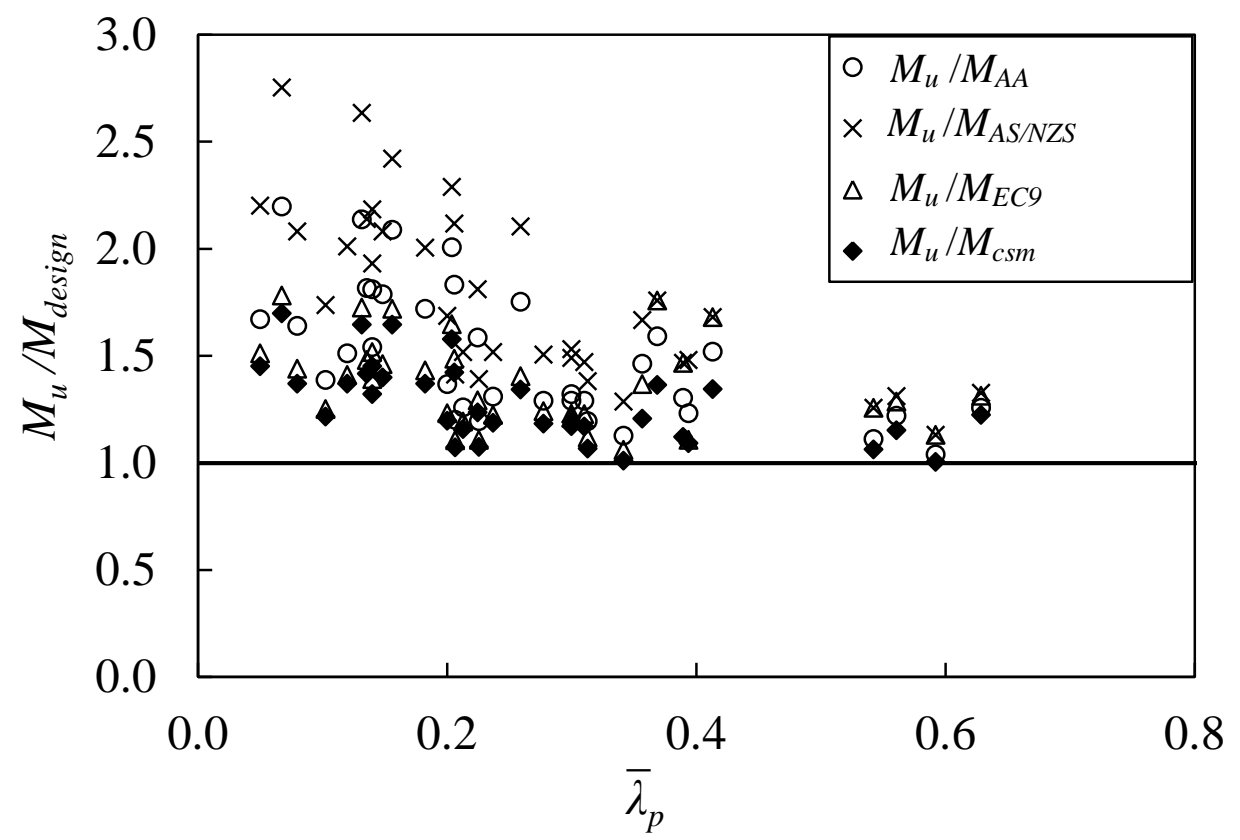

Figure 16. Comparison of three-point bending experimental and numerical results with design strengths

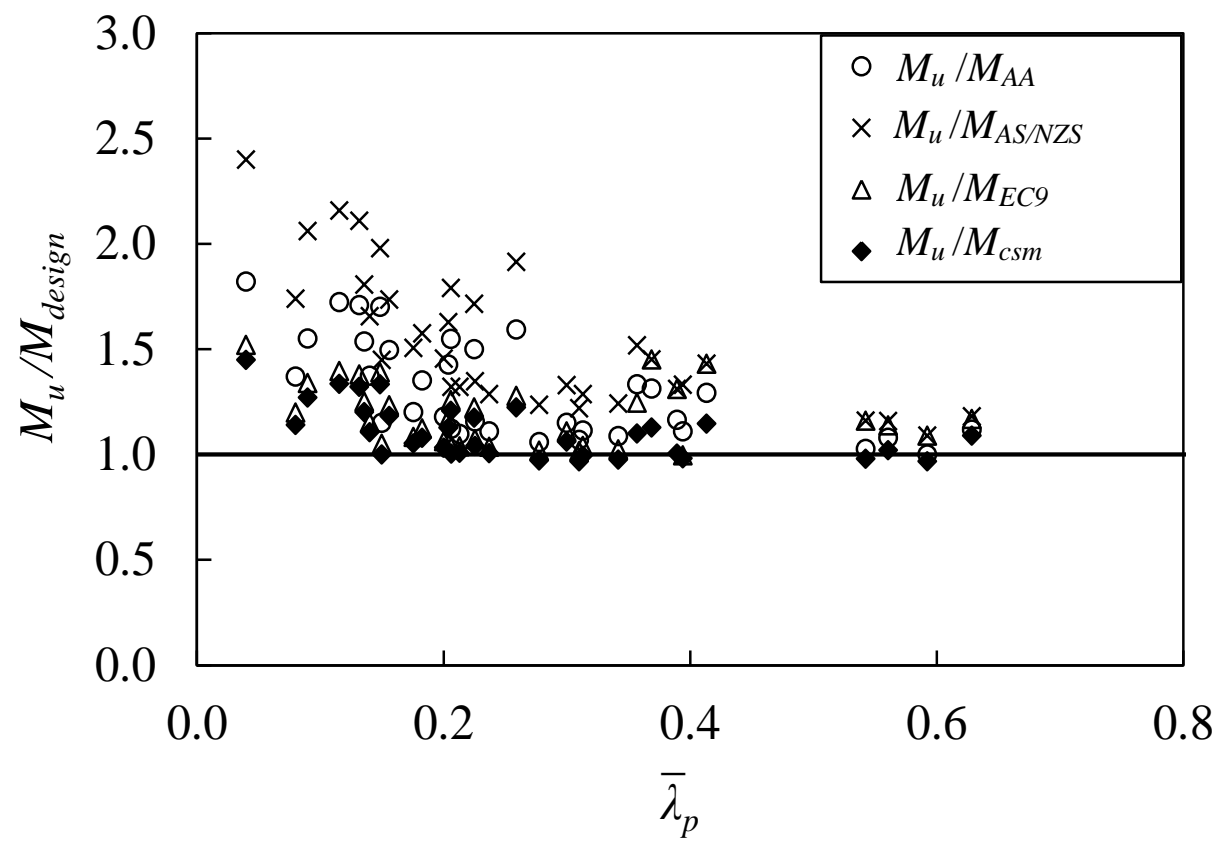

Figure 17. Comparison of four-point bending experimental and numerical results with design strengths 


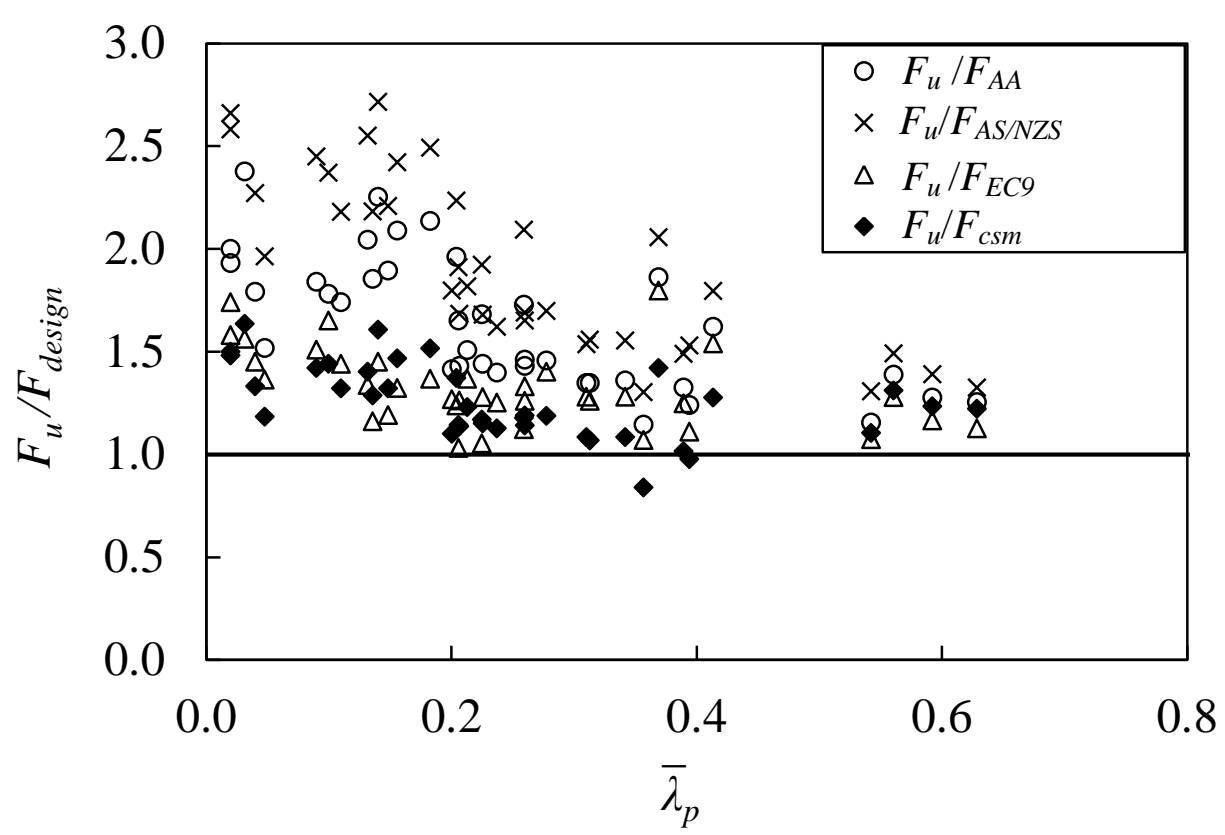

(a) Configuration I

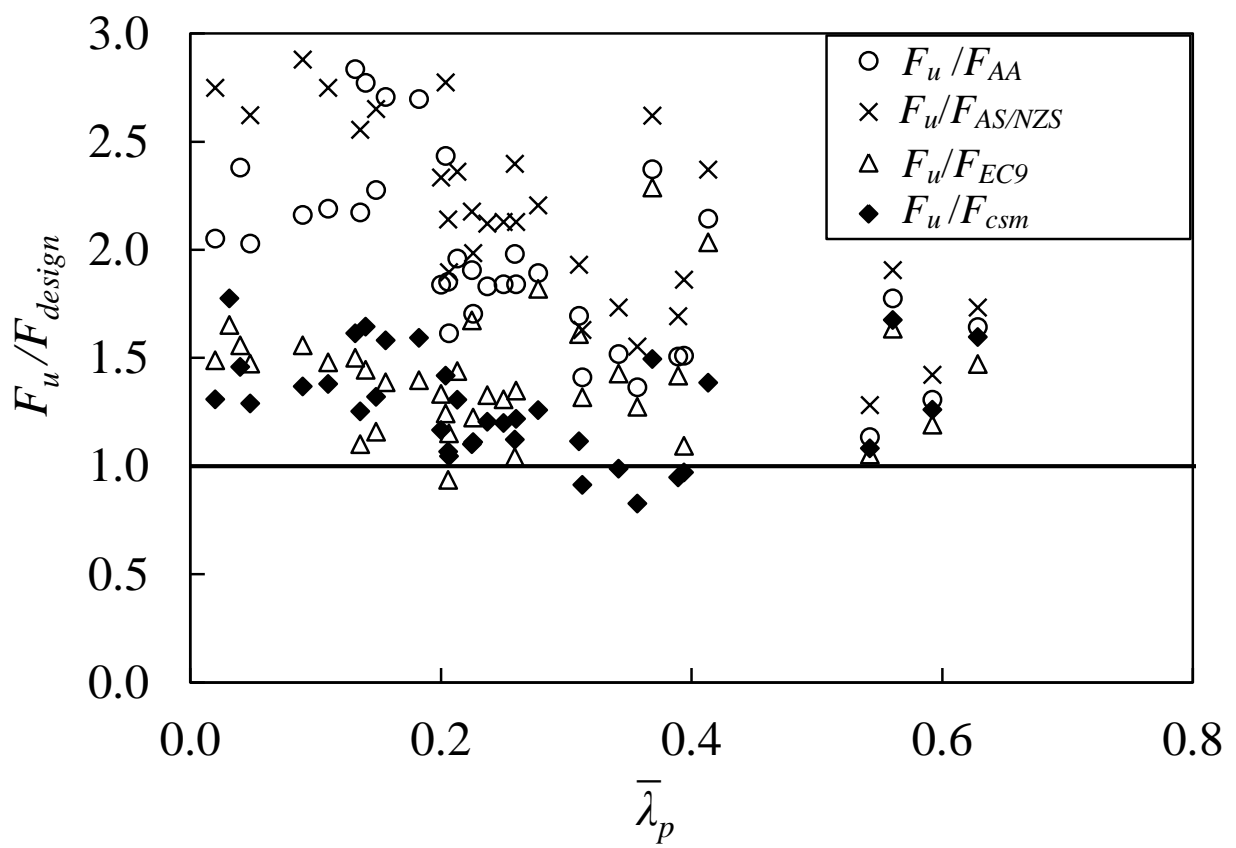

(b) Configuration II 


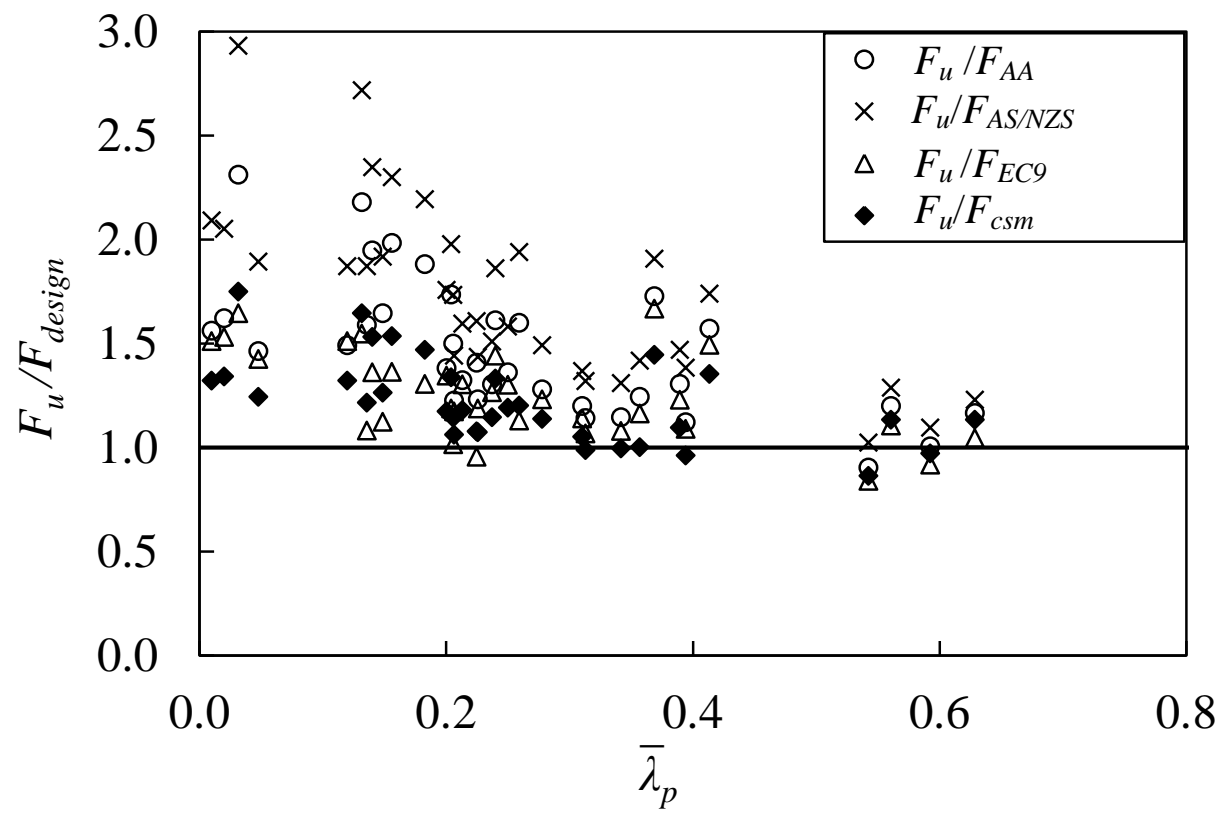

(c) Configuration III

Figure 18. Comparison of five-point bending experimental and numerical results with design strengths 